\title{
Physician Beliefs and Patient Preferences: A New Look at Regional Variation in Health Care Spending
}

\section{Citation}

Cutler, David, Jonathan Skinner, Ariel Dora Stern, and David Wennberg. "Physician Beliefs and Patient Preferences: A New Look at Regional Variation in Health Care Spending." American Economic Journal: Economic Policy 11, no. 1 (February 2019): 192-221.

\section{Published Version}

https://www.aeaweb.org/articles?id=10.1257/pol.20150421

\section{Permanent link}

http://nrs.harvard.edu/urn-3:HUL.InstRepos:41292245

\section{Terms of Use}

This article was downloaded from Harvard University's DASH repository, and is made available under the terms and conditions applicable to Open Access Policy Articles, as set forth at http:// nrs.harvard.edu/urn-3:HUL.InstRepos:dash.current.terms-of-use\#OAP

\section{Share Your Story}

The Harvard community has made this article openly available.

Please share how this access benefits you. Submit a story.

\section{Accessibility}




\section{Physician Beliefs and Patient}

Preferences: A New Look at Regional

Variation in Health Care Spending

David Cutler

Ariel Dora Stern
Jonathan Skinner

David Wennberg

Working Paper 15-090 


\section{Physician Beliefs and Patient Preferences: A New Look at Regional Variation in Health Care Spending}

David Cutler

Harvard University

Ariel Dora Stern

Harvard Business School

\author{
Jonathan Skinner \\ Dartmouth College \\ David Wennberg \\ Quartet Health
}

Working Paper 15-090 


\title{
PHYSICIAN BELIEFS AND PATIENT PREFERENCES: A NEW LOOK AT REGIONAL VARIATION IN HEALTH CARE SPENDING
}

\author{
May 7, 2017 \\ David Cutler \\ Harvard University \\ National Bureau of Economic Research \\ Jonathan Skinner \\ Dartmouth College \\ Dartmouth Institute for Health Policy \& Clinical Practice \\ National Bureau of Economic Research \\ Ariel Dora Stern \\ Harvard Business School \\ Ariadne Labs at Brigham and Women's Hospital and the Harvard T. H. Chan School of Public Health \\ David Wennberg \\ Quartet Health, New York, NY
}

\begin{abstract}
There is considerable controversy about the causes of regional variations in health care expenditures. We use vignettes from patient and physician surveys linked to fee-for-service Medicare expenditures to test whether patient demand-side factors or physician supply-side factors explain regional variations in spending. We find patient demand is relatively unimportant in explaining variation in spending after accounting for physician beliefs. Physician organizational factors matter, but the single most important factor is physician beliefs about treatment: 35 percent of Medicare end-of-life spending, 12 percent of spending for heart attack patients, and 12 percent of total Medicare spending, are associated with physician beliefs unsupported by clinical evidence.
\end{abstract}

Corresponding Author: Ariel Dora Stern

Harvard Business School

Morgan Hall 433

Boston, MA 02163

Phone: (617) 495-2332

astern@hbs.edu

Comments by Amitabh Chandra, Elliott Fisher, Mike Geruso, Tom McGuire, Joshua Gottlieb, Nancy Morden, Matt Shapiro, Allison Rosen, Gregg Roth, Pascal St.-Amour, Victor Fuchs, 2 anonymous reviewers, and seminar participants were exceedingly helpful. We are grateful to F. Jack Fowler and Patricia Gallagher of the University of Massachusetts Boston for developing the patient and physician questionnaires. Funding from the National Institute on Aging (T32-AG000186-23 and P01-AG031098 to the National Bureau of Economic Research and P01-AG019783 and U01-AG046830 to Dartmouth) and LEAP at Harvard University (Skinner) is gratefully acknowledged. De-identified survey data are available at http://tdicauses.dartmouth.edu. 


\section{Introduction}

Regional variations in rates of medical treatments are large in the United States and other countries (Skinner, et al., 2012). In the U.S. fee-for-service Medicare population, price-adjusted, per-enrollee 2014 spending varies nearly two-fold across areas. Similar price-adjusted variations are found in the under-65 population (Cooper et al., 2015), and do not appear to be explained by patient illness or poverty (Institute of Medicine, 2013).

What drives such variation in treatment and spending? One possibility is patient demand. Most studies of variations have been conducted in settings where all patients have a similar and generous insurance policy, so price differences and income effects are likely to be small. Still, heterogeneity in patient preferences for care may play a role. In very acute situations, some patients may prefer to try all possible measures to (potentially) prolong life, while others may prefer palliation and an out-of-hospital death. If people who value and demand life-prolonging treatments tend to live in the same areas, patient preference heterogeneity could lead to regional variation in equilibrium outcomes (Anthony, et al., 2009; Baker, et al., 2014; Mandelblatt, et al., 2012).

Another possible source of variation arises from the supply side. In "supplier-induced demand," a health care provider shifts a patient's demand curve beyond the level of care that the (fully informed) patient would otherwise want. This would be true in a principal-agent framework (McGuire and Pauly, 1991) if prices are high enough or income is scarce. While physician utilization has been shown to be sensitive to prices (Jacobson, et al., 2006; Clemens and Gottlieb, 2014), it would be difficult to explain the magnitude of U.S. Medicare variations using prices alone, since federal reimbursement rates do not vary greatly across areas.

Variations in supply could also occur if physicians respond to organizational pressure or peer pressure to treat patients more intensively, or maintain differing beliefs about appropriate 
treatments - particularly for conditions where there are few professional guidelines (Wennberg, et al., 1982). If this variation is spatially correlated - for example, if physicians with more intensive treatment preferences hire other physicians with similar practice styles - the resulting regional differences in beliefs could explain regional variations in equilibrium spending.

It has proven difficult to separately estimate the impact of physician beliefs, patient preferences, and other factors as they affect equilibrium healthcare outcomes, largely because of challenges in identifying factors that affect only supply or demand (Dranove and Wehner, 1994). Finkelstein, et al. (2016) addressed these challenges by following Medicare enrollees who moved to either higher or lower spending regions, finding that roughly half of the difference in spending is due to supply, and approximately half to demand. Their study, however, cannot identify the specific components of demand-side factors (e.g., preferences) nor supply-side factors (income and substitution effects, or physician beliefs).

In this study, we use "strategic" survey questions of physicians and patients (in the sense of Ameriks et al., 2011) to sidestep issues of risk-adjustment and endogeneity in estimating a unified model of overall regional Medicare expenditures. Strategic surveys have been used to estimate underlying preference parameters such as risk aversion (Barsky et al., 1997), the demand for precautionary saving (Ameriks et al., 2011) and long-term care insurance (Ameriks et al., 2016). In our study, physician incentives and beliefs are captured using detailed, scenariobased surveys that present physician-respondents with questions about their financial and practice organization, and with vignettes about how the physician would manage elderly individuals with specific chronic health conditions and a given medical and treatment history. ${ }^{1}$ Vignettes have been shown to predict actual physician behavior in clinical settings (e.g. Peabody,

\footnotetext{
${ }^{1}$ However, our surveys do not capture "deep" preference parameters as in (e.g.) Barsky et al. (1997).
} 
et al., 2000 and 2004; Dresselhaus, et al., 2004; Mandelblatt, et al., 2012; Evans, et al., 2015). In prior work, our physician surveys have been used by Sirovich, et al. (2008) and Lucas et al. (2010) to find that Medicare spending predicted physician treatment intensity, but these studies did not adjust for patient demand, nor could they answer the question of whether (and which) supply side factors explain observed variation in Medicare expenditures. ${ }^{2}$

Patient preferences are measured by a different survey of Medicare enrollees age 65 and older asking about whether they would want a variety of aggressive and/or palliative care interventions. Previous studies using this survey (Anthony, et al., 2009; Barnato, et al., 2007; Baker, et al., 2014) found a small but discernible influence of patient preferences on regional variations in health care spending. Baker et al. (2014) attempted to control for supply-side effects by using measures of actual hospital beds and physician supply, but these equilibrium quantities are endogenously determined by both supply and demand factors, leading to potential biases in estimation.

We develop an equilibrium model that specifies health care intensity (as measured by expenditures) as a function of a variety of factors specific to health care providers' and patients' preferences. To estimate this requires a multivariate model in which supply and demand factors are on the right-hand side of the equation, and overall intensity (or expenditures) are on the lefthand side. We use Hospital Referral Region (HRR)-level measures that account for both physician and patient responses within each HRR, and estimate models at the HRR level for 74 of the largest areas (covering roughly half of the Medicare population). ${ }^{3}$ We also test our model

\footnotetext{
${ }^{2}$ In these studies, because spending was on the right-hand side of the equation, and physician survey responses on the left, they could not estimate whether survey responses explain regional variations in spending, nor could the different factors (e.g., financial incentives, vignette responses) be considered in a multivariate framework.

${ }^{3}$ Ideally, we would have linked the physicians who took the survey directly to how they treated patients. We could not, however, because we did not have the permission of the physicians to link their responses.
} 
at the individual level for $100 \%$ of Medicare fee-for-service patients with acute myocardial infarction (AMI) admitted to hospital during 2007-2010. This latter sample allows us to control more accurately for individual health status and poverty, include more HRRs (137), and estimate whether higher-intensity practices are associated with better quality or health outcomes.

In our empirical exercises, we characterize physicians along two non-exclusive dimensions: those who consistently and unambiguously recommended intensive care beyond what would be indicated by current clinical guidelines (whom we refer to as "cowboys"), and those who consistently recommended palliative care for the very severely ill (whom we refer to as "comforters"). At the HRR level, we explain roughly $60 \%$ of the variation in end-of-life spending by knowing only these two measures of physician treatment intensity combined with the frequency with which physicians recommend that their patients return for routine office visits. Our results are consistent with those in Finkelstein, et al. (2016) whose estimated supplyside variations are similar to (or a bit larger than) those reported below. Conditional on the supply side, we find that in this setting, demand-side Medicare patient preferences explain about 12 percent or less of total spending, consistent with other previous studies (Anthony, et al., 2009; Barnato, et al., 2007; Baker, et al., 2014; Bederman et al., 2011, and Gogineni, et al., 2015). Previous studies have not been able to explain why some physicians are cowboys and some are comforters. We use the full sample of surveyed physicians to examine factors associated with the likelihood of being a cowboy or a comforter (relatively few physicians were both). We find that only a small fraction of physicians claim to have made recent decisions as a result of purely financial considerations. We also find that "pressure to accommodate" either patients (by providing treatments that are not needed) or referring physicians' expectations (doing procedures to keep them happy and meet their expectations) have a modest but significant 
relationship with physician beliefs about appropriate care. While many physicians do report making clinical interventions as a result of malpractice concerns, these responses do not explain variation in treatment recommendations.

Ultimately, the largest degree of residual variation appears to be explained by differences in physician beliefs about the efficacy of particular therapies. Physicians in our data have starkly different views about how to treat the same patients. These views are not strongly correlated with demographics, financial incentives, background, or practice characteristics, and are often inconsistent with evidence-based professional guidelines for appropriate care. Extrapolating from our sample of HRRs, we calculate that as much as 35 percent of end-of-life fee-for-service Medicare expenditures, 12 percent of Medicare expenditures for heart attack patients, and 12 percent of overall Medicare expenditures are explained by physician beliefs that cannot be justified either by patient preferences or by evidence of clinical effectiveness.

This paper proceeds as follows: the next section provides a graphical interpretation of the theory (with derivations in Appendix A); Section III provides data and estimation strategies, while Section IV presents the results, with particular attention paid to methodological challenges to the vignette approach raised by Sheiner (2014). Section V concludes.

\section{A Model of Variation in Medical Intensity}

We develop a simple model of patient demand and physician supply, presented in more detail in Appendix A. ${ }^{4}$ On the demand side, the patient's indirect utility function is a function of out-of-pocket prices, income, health, and preferences for care. Solving this for optimal intensity of care yields patient demand $x^{D}$. As in McGuire (2011), we assume that $x^{D}$ is the fully informed patient's demand for the quantity of care or procedures prior to any demand "inducement."

\footnotetext{
${ }^{4}$ Also see Chandra and Skinner (2012), and Finkelstein et al. (2016) which draws on our model.
} 
On the supply side, we assume that physicians seek to maximize the perceived health of their $i^{\text {th }}$ patient, $s_{i}(x)$, by appropriate choice of inputs $x$, subject to patient demand $\left(\mathrm{x}_{i}{ }^{\mathrm{D}}\right)$, financial considerations, and organizational factors. Note that the function $\mathrm{s}(\mathrm{x})$ captures both patient survival and patient quality of life, for example as measured by quality-adjusted life years (QALYs).

Individual physicians are assumed to be price-takers, but face a wide range of reimbursement rates from private insurance providers, Medicare, and Medicaid. ${ }^{5}$ We summarize the model graphically in Figure 1, with further details in Appendix A. The downward sloping curve $s^{\prime}(x)$ represents the true value of the treatment $x$ where patients are lined up in order of appropriateness. This is not a demand curve per se, but instead reflects diminishing returns to a given treatment as one works further into the population of patients less likely to benefit. The "supply" curve $\lambda$ reflects rising costs to physicians, converting dollars to QALYs by taking the inverse of the social cost-effectiveness ratio (e.g., $\$ 100,000$ per life-year). The optimum is therefore the intersection of the supply and demand curves, at Point A.

Why might the equilibrium quantity vary from A? In traditional supplier-induced demand models, reimbursement rates for procedures, taste for income, and organizational or peer effects would cause the supply curve to shift to (say) $\lambda^{*}$, leading to (in this case) higher utilization. All traditional supplier-induced demand effects work through a movement along the marginal benefit curve, $\mathrm{s}^{\prime}(\mathrm{x})$. Alternatively, patient demand could affect the quantity consumed. But so long as patients perceive the true medical benefit curve $\mathrm{s}^{\prime}(\mathrm{x})$ then demand factors such as preference, income, and prices will also serve to shift the $\lambda$ curve, so that $\lambda^{*}$ would correspond

\footnotetext{
${ }^{5}$ The model is therefore simpler than models in which hospital groups and physicians jointly determine quantity, quality, and prices, (Pauly, 1980) or in which physicians exercise market power over patients to provide them with "too much" health care (McGuire, 2011).
} 
to someone with a higher income, modest copay, or low risk aversion in the case of a risky procedure.

Less conventionally, the marginal value curve $\mathrm{s}^{\prime}(\mathrm{x})$ may differ across physicians and their patients, for example as shown in Figure 1 by $\mathrm{g}^{\prime}(\mathrm{x})$, which represents a more skilled physician. Thus Point C in Figure 1 corresponds to greater intensity of care than point A and arises naturally when the physician is more productive. For example, heart attack patients experience better outcomes from cardiac interventions in regions with higher rates of revascularization, consistent with a Roy model of occupational sorting (Chandra and Staiger, 2007). Conditional on characteristics of the patient, those treated in regions where the true productivity curve is $\mathrm{g}^{\prime}(\mathrm{x})$ will experience better health outcomes.

Alternatively, physicians may be overly optimistic with respect to their ability to perform procedures, leading to expected benefits that exceed realized benefits. Baumann, et al. (1991) have documented the phenomenon of "macro uncertainty, micro certainty" in which physicians and nurses exhibit overconfidence in the value of their treatment for a specific patient (micro certainty) even in the absence of a general consensus as to which procedure is more clinically effective (macro uncertainty). Ransohoff, et al. (2002) has noted a further psychological bias towards more aggressive treatment: If the patient gets better, the physician gets the credit, but if the patient gets worse, the physician is able to say that she did everything possible.

To see this in Figure 1, suppose the actual benefit is realized along the curve $\mathrm{s}^{\prime}(\mathrm{x})$ but the physician's perceived benefit is along the curve $\mathrm{g}^{\prime}(\mathrm{x})$. The equilibrium achieved will then be at point D: at this point, the marginal treatment harms the patient, even though the physician expects the opposite, incorrectly believing they are at point C. In equilibrium, this type of supplier behavior would appear consistent with classic supplier-induced demand, but the cause is 
quite different, and most importantly, does not require that the physician consciously "overtreats" and thus harms the patient, as is required under standard supplier-induced demand models.

How can we distinguish among these hypotheses? Using the estimation equation derived in Appendix A, we use information about patient income and preferences for treatment to capture demand effects. For supply effects, we measure traditional supplier-induced demand measures through detailed questions to individual physicians related to financial pressure, peer effects, and willingness to go along with patient demand. To measure beliefs, we use vignettes describing well-defined clinical cases. We can further distinguish between a Roy model of treatment (as in Chandra and Staiger, 2007) and one of overconfidence by testing whether patients experience higher quality care in regions with a greater fraction of cowboys and frequent follow-up visits.

\section{Data and Estimation Strategy}

In this section, we discuss the practicalities of estimating supply and demand using detailed survey data. Even detailed clinical data reveal only a subset of what the physician knows about her patient's health and reveal virtually nothing about non-clinical drivers of patient demand for health care services. We use the results of a vignette-based physician survey to proxy for physician beliefs about appropriate care (supply), and complementary vignette-based patient surveys to capture patient's preferences for care (demand). As noted earlier, Ameriks, et al. (2011) and Ameriks et al. (2016) turned to "strategic surveys" to address similar challenges in identifying supply and demand factors, although the use of strategic vignettes is relatively novel in health economics. 
We assume that the physician's responses to the vignettes are "all in" measures, reflecting physician beliefs as well as the variety of financial, organizational, and capacityrelated constraints physicians face. In other words, we assume that if a physician were motivated entirely by financial incentives, her response to the vignettes would reflect that motivation. Alternatively, one could interpret the physician's responses to the vignettes as a pure reflection of beliefs (for example, how one might answer for qualifying boards), and not as representative of the day-to-day realities of their practice. In Table 3 of Appendix C, we test this alternative explanation by including the organizational and financial variables in the estimation equations in addition to the vignette estimates, but they added little explanatory power to the regression, supporting our "all-in" assumption.

In an ideal world, patient surveys would be matched with surveys from their respective physicians. Because our data do not directly link physicians with their own patients (nor are we permitted to match physician responses to their claims data), we instead match supply and demand at the area level using HRRs. ${ }^{6}$ Our primary measure of $\mathrm{x}$, or equilibrium intensity, is the natural logarithm of risk- and price-adjusted HRR-level Medicare expenditures in the last two years of life, but we also consider overall Medicare fee-for-service spending, and patient-level data on one-year spending after admission for acute myocardial infarction (AMI).

\section{Physician Surveys}

\footnotetext{
${ }^{6}$ These HRRs are defined in the Dartmouth Atlas of Health Care, which divides the United States into 306 HRRs. Spending measures are based on area of patient residence, not where treatment is actually received, to avoid biases arising from large "destination" medical centers in regions like Boston MA or Rochester MN having unusually sick patients. (Patient residence is not unlike "differential distance" to the set of hospitals in a region.) For the analysis of urgent heart attacks (AMI), patients are highly unlikely to seek care outside of the HRR since every minute to the hospital counts for survival. For these, we link the physician and patient responses to the HRRs in which the hospitals are located.
} 
Two subsamples were drawn from the American Medical Association Database:

cardiologists and internists. ${ }^{7,8}$ A total of 999 cardiologists were randomly selected to receive the survey. Of these, 614 cardiologists responded, for a response rate of 61.5 percent. Some physicians surveyed did not self-identify as cardiologists, and others were missing crucial information such as practice type, leaving us a final sample of 598 cardiologists. The primary care physician (PCP) responses come from a parallel survey of PCPs (family practice, internal medicine, or internal medicine/family practice). A total of 1,333 primary care physicians were randomly selected to receive the survey and 967 individuals had complete responses to the survey for a response rate of 72.5 percent.

Physician survey responses may vary systematically by demographic covariates such as age and gender. Therefore, for all exercises that require aggregation of multiple physician surveys, we create demographically-adjusted, HRR-level measures of physician beliefs by adjusting all responses for observed physician characteristics (race, age, and sex).

\section{Patient Survey}

The patient survey sampling frame was all Medicare beneficiaries in the 20 percent denominator file who were age 65 or older on July 1, 2003 (Barnato et al., 2007). A random

\footnotetext{
${ }^{7}$ The document outlining "Survey Methods and Findings" (from The Center for Survey Research, University of Massachusetts Boston and Dartmouth Medical School) is available upon request; our discussion follows Sirovich et al. (2008). A mail survey of primary care physicians and cardiologists was conducted by the Center for Survey Research, affiliated with the University of Massachusetts Boston. First, focus groups concentrated on the development and wording of realistic clinical vignettes, to ensure that the questions were well understood and the answers meaningful. Next, using the masterfiles of the American Medical Association and American Osteopathic Association, we obtained a random sample of primary care physicians (self-identified as family practice, general practice, or internal medicine) or cardiologists practicing at least twenty hours per week in the United States. Residents and retired physicians were ineligible. After telephone verification of the physician's offices, each physician was mailed a survey along with a twenty-dollar bill on top, with a telephone follow-up.

${ }^{8}$ The internist sample included oversamples of physicians in four targeted cities, two in areas of low intensity (Minneapolis, MN; Rochester, NY) and two in areas of high intensity (Manhattan, NY; and Miami, FL).
} 
sample of 4,000 individuals was drawn; the response rate was 72 percent, leading to 2,882 total individuals surveyed. Since patient survey responses may also vary systematically by demographic covariates such as race and ethnicity; we create demographically-adjusted HRRlevel measures of patient preferences by adjusting all responses for observed patient characteristics (race, age, and sex).

\section{Utilization and Quality Data}

We match the survey responses to Medicare expenditure data. Our primary dependent variable is Medicare expenditures in the last two years of life for enrollees over age 65 with a number of fatal illnesses at the HRR level. ${ }^{9}$ All HRR-level measures are adjusted for age, sex, race, differences in Medicare reimbursement rates and the type of disease (including an indicator for multiple diseases). This measure implicitly adjusts for differences across regions in health status; an individual with renal failure who subsequently dies is likely to be in similar (poor) health regardless of whether she lives. End-of-life measures are commonly used to instrument for health care intensity, (e.g., Fisher et al., 2003a and 2003b; Doyle, 2011), and do not appear sensitive to the inclusion of additional individual-level risk-adjusters (Kelley et al., 2011).

A second measure is overall HRR-level Medicare expenditures from the Dartmouth Atlas of Health Care. The "Dartmouth Atlas" includes detailed data on how medical resources are distributed and used in the United States, using Medicare data to provide information and analysis about national, regional, and local markets, as well as hospitals and their affiliated physicians. Initially, we limit our attention to the 74 HRRs with a minimum of three patients, three cardiologists (average $=5.6$ ), and one primary care physician (average $=7.7$ ) surveyed. In

\footnotetext{
${ }^{9}$ These include congestive heart failure, cancer/leukemia, chronic pulmonary disease, coronary artery disease, peripheral vascular disease, severe chronic liver disease, diabetes with end organ damage, chronic renal failure, and dementia, which account for 90 percent of end-of-life spending.
} 
the main HRR-level regressions, this in turn leads to an attenuated sample of patients $(\mathrm{N}=$ $1,516)$, or an average of 20.5 patient respondents per HRR. ${ }^{10}$

We also consider a third measure of utilization: One-year Medicare expenditures after admission for acute myocardial infarction (AMI) during 2007-2010 in the fee-for-service population. The advantage of this patient-level data is that we are better able to address concerns that physician practice patterns are correlated with unobservable health status of patients. By limiting our attention to AMI patients - all of whom are seriously ill - and by using extensive risk-adjustment based on comorbidities during admission, quintiles of ZIP code income, and a HCC (hierarchical condition categories) score based on previous outpatient and inpatient diagnoses, we can capture potential differences across regions in underlying health.

We also consider quality measures. In the aggregated analysis, we use multiple Medicare measures from the "Hospital Compare" database aggregated to the HRR level. In the heart attack (AMI) data, we use two quality measures. The first is risk-adjusted one-year mortality, while the second is risk-adjusted percutaneous coronary interventions (PCI), or stents, on the day of admission. Clinical trials have shown that same-day PCI yield the greatest benefit for patients (Keeley et al., 2003; Boden et al., 2007).

\section{Patient survey vignette detail}

We use responses to five survey questions that ask patients about their likelihood of wanting unnecessary tests or cardiologist referrals in the case of new chest pain as well as preferences for comfort vs. intensive life-prolonging interventions in an end of life situation. The

\footnotetext{
${ }^{10} \mathrm{We}$ are concerned about measurement error of the constructed variables on the right-hand side of this regression specification. To address this concern, we bootstrap the entire estimation process 1,000 times to calculate all standard errors in HRR-level regressions, beginning with the construction of the HRR-level physician and patient samples, and proceeding through the HRRlevel regression analysis.
} 
exact language used in these vignettes is reproduced in Appendix B. Since the questions patients respond to are hypothetical and typically describe scenarios that have not yet happened, we think of them as preferences not affected by physician advice $\left(\mathrm{x}^{\mathrm{D}}\right)$.

Two of the questions on the patient survey relate to unnecessary care, asking respondents if they would like a test or cardiac referral even if their primary care physician did not think they needed one (Table 1). ${ }^{11}$ Overall, 73 percent of patients wanted such an unneeded test and 56 percent wanted an unneeded cardiac referral. However, there is wide variation across regions in average responses to these questions. Figure 2 shows density plots of patient preferences for the main questions in the patient survey for the 74 HRRs considered (weighted by the number of patients per HRR). Superimposed on the Figure is the simulated distribution based on 1,000 bootstrap samples, with replacement, under the null hypothesis that individuals were randomly assigned to areas. p-values for over-dispersion are reported in the last column of Table 1; these indicate that the observed variation is significantly greater than can be explained by random variation.

Three other patient questions, grouped into two binary indicators each, measure preferences for end-of-life care. One reflects patients' desire for aggressive care at the end of life: whether they would want to be put on a respirator if it would extend their life for either a week (one question) or a month (another question). The next question asks if the patient reached a point at which they were feeling bad all of the time, would they want drugs to make them feel better, even if those drugs might shorten their life. In each case, there is statistically significant variation across HRRs (Table 1).

\footnotetext{
${ }^{11}$ This question captures pure patient demand independent of what the physician wants. Note, however, that patients could still answer they would not seek an additional referral if they were unwilling to disagree with their physician.
} 
Patients' preferences are sometimes correlated across questions. For example, the correlation coefficient between wanting an unneeded cardiac referral and wanting an unnecessary test is $0.44(\mathrm{p}<.01)$. But other comparisons point to very modest associations, for example a -0.29 correlation coefficient between wanting palliative care and wanting to be on a respirator at the end of life.

Potential biases in the patient survey. One concern with these questions is that they are hypothetical, and might not reflect true patient demand. However, Anthony et al. (2009) have linked survey respondents to the individuals' Medicare claims, and found a strong link between preferences and care-seeking behavior (e.g., physician visits) at the individual level (also see Mandelblatt et al., 2012). Questions about end-of-life care may appear abstract until the patient actually faces decisions related to end-of-life care, but results are similar even with a subset of respondents age $80+$ where end-of-life scenarios and treatment decisions are likely to be more salient. Moreover, Medicare enrollees are increasingly choosing to create advanced directives that specify their end-of-life choices well before they face those decisions. ${ }^{12}$

\section{Physician survey vignette detail}

The detailed clinical vignette questions used in the physician surveys are shown in Appendix B and summary statistics are presented in Table 1. With respect to the physician surveys, prior research has established that in practice, physicians "do what they say they'd do" in a cardiac care setting. For example, physicians' self-reported testing intensity has been shown to be predictive of population-based rates of coronary angiography (Wennberg et al., 1997).

We first consider the vignette for Patient A, which asks a physician how frequently they would schedule routine follow-up visits for a patient with stable angina whose symptoms and

\footnotetext{
${ }^{12}$ According to one study, more than half of elderly Americans have advanced care directives. The primary reason for not having one was being unaware of their existence (Rao, et al., 2014).
} 
cardiac risk factors are well controlled on current medical therapy (for cardiologists) or a patient with hypertension (for primary care physicians). The response is unbounded, and expressed in months, but in practice individual physician responses ranged from 1 to 24 months. Figure $3 \mathrm{a}$ presents a HRR-level histogram of averages from the cardiology survey for 74 HRRs.

How do these responses correspond to guidelines for managing such patients? The 2005 American College of Cardiology/American Heart Association [ACC/AHA] guidelines (Hunt et al., 2005) - what most cardiologists would have considered the "Bible" in cardiology at the time the survey was fielded - recommended follow-up every 4-12 months. However, even with these broad recommendations, we find that 19 percent of cardiologists are "high follow-up" in the sense of recommending visits more frequently than every 4 months, and 2 percent are "low follow-up" and recommend visits less frequently than every 12 months. These physicians were geographically clustered in a subset of HRRs $(\mathrm{p}<.01$ in a test of the null of no correlation) and the distribution of high follow-up cardiologists across HRRs is shown in Figure $3 b$.

The equivalent measure for PCPs is recommended follow-up frequency for a patient with well-controlled hypertension. The Seventh Report of the Joint National Committee on Prevention, Detection, Evaluation, and Treatment of High Blood Pressure (U.S. Department of Health and Human Services, 2004), which would have been the most current guideline recommendation at the time, suggests follow-up for this type of patient every 3-6 months based on expert opinion. Based on this range, 3 percent of PCPs in our sample are "high follow-up" and 10 percent are "low follow-up" doctors. ${ }^{13}$

\footnotetext{
${ }^{13}$ Office visits are not a large component of physicians' incomes (or overall Medicare expenditures). Thus any correlation between the frequency of follow-up visits and overall expenditures would most likely be because frequent office visits are also associated with additional highly remunerated tests and interventions (such as echocardiography, stress imaging studies, and so forth) that further set in motion the "diagnostic-therapeutic cascade" (Lucas, et al., 2008).
} 
The next two vignettes focus on patients with heart failure, a much more expensive setting. Heart failure is also a natural scenario to consider because it is common, the disease is chronic, its prognosis is poor, and treatment is expensive. Vignettes for both Patients B and C ask questions about the treatment of Class IV heart failure, the most severe classification and one in which patients have symptoms at rest. In both patient scenarios the vignette patient is on maximal (presumably optimal) medications, and neither patient described is a candidate for revascularization: Patient B has already had a coronary stent placed without symptom change, and Patient $\mathrm{C}$ is explicitly noted to not be a candidate for this procedure. The key differences between the two scenarios are the respective patients' ages ( 75 for Patient B, 85 for Patient C), the presence of asymptomatic non-sustained ventricular tachycardia in Patient B, and severe symptoms that resolve partially with increased oxygen in Patient $\mathrm{C}$.

Cardiologists in the survey were asked about various interventions as well as palliative care for each of these patients. For Patient B, they were given five choices: three intensive treatments (repeat angiography; implantable cardiac defibrillator [ICD] placement, and pacemaker insertion), one involving medication (antiarrhythmic therapy), and palliative care. For Patient $\mathrm{C}$, each physician is also presented with three intensive options (admit to the ICU/CCU, placement of a coronary artery catheter, and pacemaker insertion), two less aggressive options (admit to the hospital [but not the ICU/CCU] for diuresis, and send home on increased oxygen and diuretics), and palliative care. In each scenario, cardiologists separately reported their likelihood of recommending each potential intervention on a 5-interval range from "always / almost always" to "never." Each response is recorded independently of other responses, so for example, physicians could "frequently" recommend both palliative care and one (or more) intensive intervention(s). 
Beginning with the obvious, regardless of the religious, political or moral persuasion of the physician, both patients described in the survey deserve a frank conversation about their prognosis and an ascertainment of their preferences for end-of-life care. The one-year mortality for each vignette patient is statistically expected to be as high as 50 percent (Ahmed et al., 2006). If compliant with guidelines, therefore, all physicians should have answered "always/almost always", or at least "most of the time," when reporting their likelihood of initiating or continuing discussions about palliative care. ${ }^{14}$

For Patient B, only 29 percent of cardiologists responded that they would initiate or continue discussions about palliative care "most of the time" or "always/almost always." For Patient C, 44 percent of cardiologists and 47 percent of primary care physicians were likely to recommend this course of action "most of the time" or "always/almost always." In both cases, physicians' recommendations fall far short of clinical guidelines. We classify the doctor as a "comforter" if the physician would discuss palliative care with the patient "always / almost always" or "most of the time" for both Patients B and C (among cardiologists) or for Patient C only (among primary care physicians, who did not have Patient B's vignette in their survey). In our final sample, 27 percent of cardiologists and 47 percent of primary care physicians met this definition of a comforter.

We now turn to more medically intensive aspects of patient management. The language in the vignettes was carefully constructed to relate to the contemporaneous clinical guidelines. Several key aspects of Patient B rule out both the ICD and pacemaker insertion ${ }^{15}$ and indeed the

\footnotetext{
${ }^{14}$ According to the AHA-ACC directives, "Patient and family education about options for formulating and implementing advance directives and the role of palliative and hospice care services with reevaluation for changing clinical status is recommended for patients with HF [heart failure] at the end of life." (Hunt, et al., 2005, p. e206).

${ }^{15}$ This includes his advanced stage, his severe (Class IV) medication refractory heart failure, and the asymptomatic non-sustained nature of the ventricular tachycardia.
} 
ACC-AHA guidelines explicitly recommend against the use of an ICD for Class IV patients (Hunt et al., 2005; p. e206).

Since Patient $\mathrm{C}$ is already on maximal medications and is not a candidate for revascularization, the physician's goal should be to keep him as comfortable as possible. This should be accomplished in the least invasive manner possible (e.g., at home), and if that is not possible, in an uncomplicated setting, for example during admission to the hospital for simple diuresis. According to the ACC/AHA guidelines, no additional interventions are appropriate for this patient. ${ }^{16}$ In fact, even a "simple" but invasive test, the pulmonary artery catheter, has been found to be of no marginal value over good clinical decision making in managing patients with congestive heart failure (CHF), and could even cause harm (ESCAPE, 2005).

Despite these guideline recommendations, physicians in our data show a great deal of enthusiasm for additional interventions. For Patient B, over one quarter of the cardiologists surveyed (28 percent) would recommend a repeat angiography at least "some of the time." Similarly, 62 percent of cardiologists would recommend an ICD "most of the time," or "always/almost always," while 45 percent would recommend a pacemaker at least "most of the time." For Patient C, 18 percent of cardiologists would recommend an ICU/CCU admission, 2 percent would recommend a pulmonary artery catheter and 14 percent would recommend a pacemaker at least "most of the time."

Cardiologists' responses on aggressive interventions are highly correlated across Patients B and C. Of the 28 percent $(\mathrm{N}=170)$ of cardiologists in the sample who would "frequently" or "always/almost always" recommend at least one of the high-intensity procedures for Patient C, 90 percent $(\mathrm{N}=153)$ would also frequently or always/almost always recommend at least one

\footnotetext{
${ }^{16}$ Clinical improvement with a simple intervention (increasing his oxygen) also argues against more intensive interventions.
} 
high-intensity intervention for Patient B. We use this overlap to define a "cowboy" cardiologist as a cardiologist who would recommend at least one of the three possible intensive treatments for both Patients B and C at least "most of the time." Because Vignette B was not presented to primary care physicians, we use their responses to Vignette $\mathrm{C}$ to categorize them using the same criteria. In total, 25 percent of the cardiologists in our sample are classified as cowboys, as are 22 percent of primary care physicians.

All told, we consider four measures of physician behavior (supply side variables): high or low frequency of follow-up visits, a dummy variable for being a cowboy, and a dummy variable for being a comforter. How are these measures related to one another? Table 2 shows that physicians with a low follow-up frequency are more likely to be comforters and less likely to be cowboys than physicians with a high follow-up frequency. Similarly, cowboy physicians are unlikely to be comforter physicians (even though 8 percent of doctors were classified as both).

\section{Estimation results}

Our first set of regression results runs a "horse-race" between area-level supply and demand factors to asses which set of factors can better explain actual regional expenditures, for a variety of datasets. In our second set of estimates, we return to the full sample of physicians to understand why they hold the beliefs they do by relating individual physician vignette responses to physicians' financial and organizational incentives.

Do Survey Responses Predict Regional Medicare Expenditures?

We begin with end-of-life spending as a measure of utilization that is most likely to be sensitive to differences across regions for patients, like those in our vignettes, at a high risk of 
death. ${ }^{17}$ Figure 4 shows scatter plots of area-level end of life spending vs. our measures of supply and demand for care. The measures included here are the fraction of all physicians in the area who are cowboys (panel a), the fraction of physicians who are comforters (panel b), the fraction of physicians who recommend follow-up more frequently than recommended guidelines (panel c), and the share of patients who desire more aggressive care at the end of life (panel d). Each circle represents one HRR, with its size is proportional to the physician survey sample size.

In the case of the three supply-side variables in Figure 4, the results are consistent with their meaningful role in determining spending: despite the relatively small sample sizes of physicians in each HRR, end of life spending is positively related to the cowboy ratio, negatively related to the comforter ratio, and positively related to the fraction of doctors recommending follow-up visits more frequently than clinical guidelines indicate. The demand variable, in contrast, is not strongly related to spending: the data points form more of a cloud than a line.

Table 3 explores these results more formally with regression estimates of the natural log of end-of-life expenditures in the last two years of life (columns 1-6) and overall Medicare expenditures (column 7). The statistical significance of all results is robust to adjusting standard errors using 1,000 bootstrap samples of patient and physician surveys. As the first column shows, the local proportion of cowboys and comforters explains 34 percent of the observed regional variation in risk-adjusted end-of-life spending. Further, the estimated magnitudes are large: increasing the percentage of cowboys by one standard deviation (15 percentage points) is associated with a 12 percent increase in end-of-life expenditures, while increasing the fraction of comforters by one standard deviation (18 percentage points) implies a 5.8 percent decrease in those expenditures. These relationships between spending and the local fractions of cowboys

\footnotetext{
${ }^{17}$ End-of-life spending is also highly correlated with prospective measures such as spending for advanced lung-cancer (Keating et al., 2016).
} 
and comforters are robust to a number of alternative specifications. ${ }^{18}$ Results also hold when both physician samples are analyzed separately (Appendix C, Tables 1 and 2).

Column 2 of Table 3 shows that the indicator for the share of physicians recommending high frequency follow-up is also a meaningful predictor of HRR-level end-of-life spending: conditional on the fraction of cowboys and comforters, an increase of one standard deviation (12 percentage points) of physicians who prefer to see patients more frequently than guidelines suggest would be predicted to increase end-of-life spending by 13 percent. While the low frequency follow-up coefficient is meaningful in magnitude - implying roughly a 3 percent reduction in spending for a one standard deviation increase in low follow-up physicians - it is not statistically significant. Notably, the combination of just these four variables about supplier beliefs alone can explain over 60 percent of the observed end-of-life spending variation in the 74 HRRs in this sample. ${ }^{19}$

The next two columns add measures of patient preferences at the HRR level to the regressions: the share of patients wishing to have unneeded tests in a cardiac setting, the share of patients wanting to see an unneeded cardiologist, the share of patients preferring aggressive endof-life care, and the share preferring comfortable end-of-life care. None of these variables are statistically significant at the 5 percent level. Even excluding the physician belief variables entirely, as in column 6, the R-squared value from the regression incorporating patient preference variables alone is just 0.12 . In further sensitivity analyses, we also considered using

\footnotetext{
${ }^{18}$ In robustness tests not presented, we further find that the observed patterns are robust to the exclusion of "small cells" (HRRs with fewer than eight physician surveys), to controlling for percent poverty at the HRR level, and to re-weighting HRRs by their patient population.

${ }^{19}$ As Black, et al. (2000) note, the OLS estimate is a lower bound and under weak assumptions, the expected value of the OLS parameter estimate is of smaller magnitude than the true parameter. (The $\mathrm{R}^{2}$ is also a lower bound owing to measurement error.)
} 
alternate and/or additional measures of patient demand recovered from the patient survey, or financial variables from the physician surveys; these alternate measures do not increase the explanatory power of our regression models, nor are the coefficients related to patient demand factors statistically significant at conventional levels, when predicting Medicare spending in the last two years of life. ${ }^{20}$

Regressions for the natural log of total Medicare expenditures are presented in the final column of Table 3; coefficients are similar but in this specification, the role of patient preferences for comfort-oriented care emerges as statistically significant, consistent with Finkelstein et al. (2016), who find that patient demand explains a significant share of Medicare spending in a non-end-of-life context.

We further consider the possibility that physicians' aggressiveness in end-of-life care may be related to overall quality. We analyze the range of quality measures from the CMS Hospital Compare data (December 2005 data release. ${ }^{21}$ averaged at the HRR level), but find few statistically significant correlations between the fraction of aggressive physicians (cowboys) and quality measures. Of the seventeen quality measures considered, only two ${ }^{22}$ have a statistically significant correlation with the fraction of cowboys in a region (and those were negative correlations); the remainder showed no significant correlation with the cowboy fraction.

\footnotetext{
${ }^{20}$ Nor were our results driven by differences between east-coast versus west-coast medical practice; similar results were obtained when east and west coasts were estimated separately. It is also possible that there is an interaction effect between patient preferences and physician beliefs - for example if aggressive physicians interact with patients with preferences for aggressive care - to generate even more utilization (or conversely for comforter physicians and patients who demand palliative care to interact and reduce care provided in a mutually reinforcing way). We test this in Appendix C, Table C4, but do not find strong evidence for this hypothesis.

${ }^{21}$ Data available at: https://data.medicare.gov/data/archives/hospital-compare

${ }^{22}$ AMI patients with left ventricular systolic dysfunction (and without contraindications) who were prescribed an ACE inhibitor or an ARB at hospital discharge and Pneumonia patients who receive their first dose of antibiotic within 4 hours of arrival at the hospital.
} 


\section{Expenditures and Outcomes in Acute Myocardial Infarction}

We next consider expenditures and outcomes in a sample of AMI patients. By focusing on physician vignette measures, which we think are of primary importance in acute and postacute treatment decisions for these patients, we were able to expand the sample size to 137 HRRs accounting for $71 \%$ of the entire AMI sample $(\mathrm{N}=560,392) .{ }^{23}$ Spending measures are adjusted for differences across regions in prices using the Gottlieb et al. (2010) method, and all regressions are clustered at the HRR level. Summary statistics are presented in Table 5 of Appendix C.

Regression estimates are presented in Table 4, with expenditures in levels, in column 1, and in logs in column 2. As expected, the risk-adjustment HCCs are large in magnitude and highly significant, but conditional on health status, ZIP income quintiles are all generally small in magnitude. The coefficients for cowboy $(\$ 7,719)$ and high revisit rates $(\$ 16,602)$ are large relative to the mean value $(\$ 46,268)$ and highly statistically significant. There is a strong negative coefficient for comforters $(-\$ 2,825)$, and while the coefficient for low revisit rates ($\$ 3,566)$ is in the expected direction, the estimate is not statistically significant at conventional levels. Similar results are shown in the log regression, albeit with coefficients that imply slightly smaller proportional effects.

One concern with our sample of 137 HRRs is that many of the HRRs have just a handful of physicians, leading to likely measurement error in average responses by HRR. We therefore weight the regressions by the number of physicians in the survey, with results shown in columns 3 and 4 . The coefficients that are generally larger in magnitude than the unweighted data; the

\footnotetext{
${ }^{23}$ In sensitivity analysis, not reported, we also included patient demand variables, but none were significant in any of the regression analyses, except for one: The patient aggressiveness measure was associated with a lower probability of early PCI (stenting), the reverse of what one might expect.
} 
coefficient on Cowboy is $\$ 10,729$, and for high follow-up, the coefficient is $\$ 22,579$; both are highly statistically significant. That is, high-follow-up physicians are associated with roughly $50 \%$ higher rates of one-year expenditure for AMI patients.

Finally, Table 4 provides evidence on the hypothesis that regions with a greater share of cowboy or high follow-up physicians experience higher quality health-care for AMI patients. Column 5 provides estimated marginal effects from Probit models of one-year survival, while column 6 provides similar marginal effects for PCI, or stenting, that occurs on the day of admission for AMI. The survival mean is 67.8 percent, and the PCI mean is 26.0 percent. In the survival regression, the HCC risk adjuster is a remarkably strong predictor of survival (29.2 percentage point lower survival rates in the least healthy HCC quintile compared to the healthiest quintile). Conditional on the HCC index and other risk factors, income is modestly associated with survival (2.9 percentage point higher survival in the $5^{\text {th }}$ income quintile compared to the first). None of the physician variables are individually significant predictors of survival, and the p-value for the F-test is 0.41 .

Consider next the estimates for early PCI, in column 6 of Table 4. Neither the cowboy nor comforter variables are associated with early PCI. Follow-up rates, by contrast, are associated negatively with early PCI; the coefficient on high-follow-up physicians suggests a 6.2 percent lower early PCI rate, with the converse true for low-follow-up physicians (The F-test of all four variables is jointly significant at the 0.01 level). Along with results reported above, these suggest a lack of association or negative association between physician intensity and quality of care, which is consistent with our model in which physician beliefs unsupported by clinical evidence can increase utilization, but with no beneficial impact for patients.

What factors predict physician responses to the vignettes? 
To this point, we have shown that aggregated physician vignette responses explain regional patterns in spending, and that these responses vary across areas far more than would be expected given random variation. But this raises the question: what explains variation in physician treatment beliefs? In this section, we use the entire sample of physicians to test for the relative importance of financial and organizational factors in explaining physician recommendations. We interpret the residual, conditional on financial and organizational factors, as "beliefs."

Various measures of financial circumstances relating to reimbursement are reported in Table 1 for all physicians. We focus on three of these in particular: the share of patients for whom they are reimbursed on a capitated basis (on average, 15 percent), the share of patients whose primary health insurance is Medicare (42 percent), and the share of a physician's patients on Medicaid (10 percent), with capitated payment and Medicaid generally associated with lower marginal reimbursement.

A second set of questions asks about characteristics of the physician and her practice: 29 percent work in small practices (solo or 2-person), 57 percent work in single or multi-specialty group practices, and 13 percent work in HMOs or hospital-based practices. We also observe a number of characteristics about the physician, including age, gender, whether she is board certified, and the number of days per week she spends seeing patients.

Third, the survey asks about a physician's self-assessed responsiveness to external incentives over the past year, including how frequently, if ever, in the past 12 months she had intervened on a patient for non-clinical reasons. We create a set of binary variables that indicates whether a physician responded to each set of incentives at least "sometimes" (i.e. "sometimes" or "frequently") over the past year. Among cardiologists, 31 percent reported that they had 
sometimes or frequently performed a cardiac catheterization because of the expectations of the referring physician and 38 percent of all physicians reported having intervened medically because of a colleague's expectations (Table 1).

Table 5 presents coefficients from a linear probability model with HRR-level random effects for three regressions at the physician level. Our dependent variables are binary indicators for whether the physician is a cowboy (column 1), a comforter (column 2), or recommends high frequency follow-up (column 3). In each model, we include basic physician demographics: age, gender, board certification status, whether the physician is a cardiologist, days per week spent seeing patients, as well as cardiologists per 100,000 Medicare beneficiaries.

Notably, some physician characteristics are predictive of physician types: cardiologists are significantly more likely (over 20 percentage points) to be high follow-up doctors and older physicians in the sample are somewhat more likely to be cowboys and high follow-up doctors. Physicians practicing more days per week are somewhat more likely to be comforters.

A substitution effect would imply that lower incremental reimbursements associated with treating a larger share of Medicaid and capitated patients would lead to fewer interventions and more palliative care; an income effect would suggest the opposite. Table 5 shows that physicians with a larger fraction of Medicaid and (but not capitated patients) are more likely to be cowboys, supporting a stronger income effect.

Some organizational factors are clearly associated with physician beliefs about appropriate practice. Physicians in solo or 2-person practices are far more likely to be both cowboys and high follow-up doctors than physicians in single or multi-specialty group practices or physicians who are part of an HMO or a hospital-based practice. Whether cardiologists accommodate referring physicians - a financial factor (since cardiologists benefit financially 
from future referrals) as well as an organizational one - is a positive predictor of cowboy status among cardiologists. ${ }^{24}$ Self-reported responsiveness to malpractice concerns are high (nearly $40 \%$ of physicians report intervening for this reason), but are not statistically significant predictors of physician type in this sample. ${ }^{25}$

The explanatory power of these regressions is quite modest - between 4 and 16 percent suggesting that a considerable degree of the remaining variation is the consequence of physician beliefs regarding the productivity of treatments, rather than behaviors systematically related to financial, organizational, or other factors.

\section{Challenges to Identification}

One concern with the use of vignettes is that the vignette responses are acting as a proxy for unobservable health status, and so regions with more cowboys are also regions with (unobservably) sicker patients (Sheiner, 2014). We approach this hypothesis in several ways.

We start by examining whether physicians appear to treat patients with different demographic backgrounds differently. Arber et al. (2006) employed actors of differing race, class and gender to read identical scripts describing their symptoms related to CHF. After the "patients" read the scripts, physicians were asked, among other things, how long before the patient should return for a follow-up visit. The authors found no significant differences by race or income (e.g., African-American janitors versus white schoolteachers), although they did find differences by gender. In other words, there was no evidence that physicians were "filling in" characteristics by race or socioeconomic status when making follow-up recommendations.

\footnotetext{
${ }^{24}$ Note that the question on responding to referring doctor expectations appeared in the cardiologist survey only, and so reflects the preferences of cardiologists only; the cardiology dummy variable therefore reflects both the pure effect of being a practicing cardiologist, and a secondary adjustment arising from the referral question being set to zero for all primary care physicians.

${ }^{25}$ Perhaps because procedures performed on high-risk patients (such as Patients B and C) can increase the risk of a malpractice suit (Currie and MacLeod, 2008).
} 
A related hypothesis is that physicians treat all their patients as if they had the average health of patients in their region or practice. Thus, physicians who practice in poor areas will recommend more care because their patients are on average sicker. Empirically, however, physicians in the quartile of HRRs with the greatest level of poverty are less likely to recommend a follow-up visit within 3 months than the average physician, although the results are not significant. $^{26}$ In unreported regressions, we confirm that our results in Table 3 are robust to controlling for percent poverty at the HRR level.

Nor is it the case that more intensive treatment is on average more medically appropriate in this setting. For example, one of the "cowboy" options available for Individual B, a 75-yearold with Class IV (the most severe) heart failure is an implantable defibrillator. Professional societies uniformly recommend against its use for Class IV CHF patients - and indeed, Medicare refuses to pay for it -because the risks (faulty leads, infections, painful death) outweigh the benefits for the average patient, and it would be even less appropriate for patients with poor access to follow-up care and higher mortality risk, as one might find in low-income states.

Finally, Sheiner (2014) notes that better practice styles might be associated with higher social capital (e.g., Skinner and Staiger, 2007), and thus proxy once again for unobservable health. Yet we find a strong association in the Medicare AMI sample between physician beliefs and expenditures even after adjustment for the HCC score, which is highly predictive (and some would argue, over-predictive) of Medicare expenditures. ${ }^{27}$ Further, Finkelstein et al. (2016) find that our measure of "cowboy cardiologists" is significantly associated with changes in Medicare

\footnotetext{
${ }^{26}$ Similarly, there was a negative but statistically insignificant association between the fraction of a physician's Medicaid patients and the likelihood of a quick follow-up visit.

${ }^{27}$ The HCC score has been shown to reflect regional intensity of spending, because higher intensity in spending leads to more diagnosis and hence a higher HCC score (Song et al., 2010; Finkelstein et al., 2016). This would suggest that our estimates of the importance of physician beliefs are biased downward.
} 
expenditures in their sample of movers. This again is consistent with the view that physician beliefs exerts a large impact on health care utilization.

\section{Discussion and Conclusion}

While there is a good deal of regional variation in medical spending and care utilization in the U.S. and elsewhere, there is little agreement about the causes of such variations. Do they arise from variation in patient demand, variation in physician beliefs or economic factors, or both? In this paper, we find that regional measures of patient demand as measured by responses to a nationwide survey have only modest predictive associations with regional end-of-life expenditures (Anthony, et al., 2009; Baker et al., 2014). Instead, we find that physician beliefs are highly associated with Medicare spending, even after adjusting for conventional demographic, organizational, and financial incentives facing physicians. Indeed, these beliefs are nearly orthogonal to the conventional organizational and financial incentives for physicians that play a central role in most economic models of physician behavior.

How much would Medicare expenditures change in a counterfactual setting in which there were no cowboys, all physicians were comforters, and all physicians met guidelines for follow-up care? While we recognize the conjectural nature of this calculation and the fact that it is limited to the Medicare fee-for-service population in the HRRs where we have survey data, our estimates imply that in total, these regions would see a decline of 35 percent in end-of-life Medicare expenditures, 12 percent for spending following AMI, and up to 12 percent in total Medicare expenditures. ${ }^{28}$

${ }^{28}$ The AMI estimates use column 3 from Table 4. 
Finally, we consider the factors that lead physicians to have different preferences. We find that the traditional factors in supplier-induced demand models, such as the fraction of patients paid through capitation (or on Medicaid), or physicians' responsiveness to financial factors, play a relatively small role in explaining equilibrium variations in utilization patterns in our context. Organizational factors, such as accommodating colleagues, help to explain only a small amount of observed variation in individual intervention decisions. Instead, unexplained differences in physician beliefs about the effectiveness of treatments account for the lion's share of inter-regional variation in Medicare expenditures. ${ }^{29}$

Unfortunately, we cannot shed light on how these differences in physician beliefs arise. Previous hypotheses have included variation in medical training (Epstein and Nicholson, 2009) or their personal experiences with different interventions (Levine-Taub, et al., 2015). Yet simple heterogeneity in physician beliefs alone cannot explain regional variation in expenditures, since the observed regional patterns in physician beliefs exhibit far greater inter-region variation than would be expected due to chance alone. Rather, spatial correlation in physician beliefs is required in order to explain the regional patterns we observe. We do find that physicians' propensity to intervene for non-clinical reasons is related to the expectations of physicians with whom they regularly interact, a result consistent with network models. Similarly, Molitor (2016) finds that cardiologists who move to more or less aggressive regions change their practice style to better conform to local norms. However, we are still left with questions as to how and why some regions become more aggressive than others.

\footnotetext{
${ }^{29}$ This result is consistent with Epstein and Nicholson (2009), who find large variations in Cesarean section surgical rates among obstetricians within the same practice, and with Chassin's (1993) "Enthusiasm Hypothesis" - that regional differences in the use of health care services are caused by differences in the prevalence of physicians who are enthusiasts for those services.
} 
Our results do not imply that economic incentives are unimportant. Clearly, changes in payment margins have a large impact on behavior, as has been shown in a variety of settings.

But the prevalence of geographic variations in European countries, where economic incentives are often nearly entirely blunted (Skinner, 2012), is also consistent with the view that physician beliefs play a large role in explaining such variations. A better understanding of both how physician beliefs form, and how they can be changed, is therefore a key challenge for future research. 


\section{References}

Ahmed Ali, Wilbert S Aronow, and Jerome L Fleg, 2006. "Higher New York Heart Association Classes and Increased Mortality and Hospitalization in Heart Failure Patients with Preserved Left Ventricular Function," American Heart Journal, 151(2): 444-450.

Ameriks, John, Andrew Caplin, Steven Laufer, and Stijn van Nieuwerburgh, 2011. "The Joy of Giving or Assisted Living? Using Strategic Surveys to Separate Public Care Aversion from Bequest Motives," Journal of Finance, 66(2) (April), 519-561.

Ameriks, John, Joseph Briggs, Andrew Caplin, Matthew D. Shapiro, and Christopher Tonetti, 2016. "Late-in-Life Risks and the Under-Insurance Puzzle.” NBER Working Paper No. 22726 (November).

Anthony, Denise L., M. Brooke Herndon, Patricia M. Gallagher, Amber E. Barnato, Julie PW Bynum, Daniel J. Gottlieb, Elliott S. Fisher, and Jonathan S. Skinner. "How much do patients' preferences contribute to resource use?."Health Affairs 28, no. 3 (2009): 864-873.

Arber, Sara, John McKinlay, Ann Adams, Lisa Marceau, Carol Link, and Amy O'Donnell. "Patient characteristics and inequalities in doctors' diagnostic and management strategies relating to CHD: a video-simulation experiment." Social Science \& Medicine 62, no. 1 (2006): 103-115.

Baker, Laurence C., M. Kate Bundorf, and Daniel P. Kessler, 2014. "Patients' Preferences Explain a Small but Significant Share of Regional Variation in Medicare Spending," Health Affairs 33(6), pp. 957-63.

Barnato, Amber E., M. Brooke Herndon, Denise L. Anthony, Patricia M. Gallagher, Jonathan S. Skinner, Julie PW Bynum, and Elliott S. Fisher. "Are regional variations in end-of-life care intensity explained by patient preferences?: A Study of the US Medicare Population." Medical care 45, no. 5 (2007): 386.

Barsky, Robert B., F. Thomas Juster, Miles S. Kimball, and Matthew D. Shapiro, 1997. "Preference Parameters and Behavioral Heterogeneity: An Experimental Approach in the Health and Retirement Study." The Quarterly Journal of Economics 112(2): 537-579.

Baumann, Andrea O., Raisa B. Deber, Gail G. Thompson, 1991, "Overconfidence Among Physicians and Nurses: The 'Micro-Certainty, Macro-Uncertainty' Phenomenon," Social Science and Medicine 32(1): 167-74.

Bederman, S. Samuel, Peter C. Coyte, Hans J. Kreder, Nizar N. Mahomed, Warren J. McIsaac, and James G. Wright, 2011, "Who's in the Driver's Seat? The Influence of Patient and Physician Enthusiasm on Regional Variation in Degenerative Lumbar Spinal Surgery: A Population-based Study." Spine 36(6): 481-489. 
Black, Dan A.; Mark C. Berger; Frank A. Scott, 2000. "Bounding Parameter Estimates with Nonclassical Measurement Error," Journal of the American Statistical Association, Vol. 95(451), pp. $739-748$.

Boden, William E., O'Rourke, Robert A., Teo, Koon K., and the COURAGE Trial Research Group, 2007. "Optimal Medical Therapy with or without PCI for Stable Coronary Disease" N England Journal of Medicine 356: 1503-1516.

Campbell, Eric G., Sowmya R. Rao, Catherine M. DesRoches, Lisa I. Iezzoni, Christine Vogeli, Dragana Bolcic-Jankovic, and Paola D. Miralles, "Physician Professionalism and Changes in Physician-Industry Relationships From 2004 to 2009," Archives of Internal Medicine, 170(20), pp. 1820-26.

Chandra, Amitabh, and Douglas O. Staiger. 2007. "Productivity Spillovers in Healthcare: Evidence from the Treatment of Heart Attacks," Journal of Political Economy 115, 103-140.

Chandra, Amitabh, and Jonathan Skinner, 2012, "Productivity growth and expenditure growth in U.S. Health care,” Journal of Economic Literature 50(3) (September): 645-80.

Chandra, Amitabh, Dhruv Khullar, and Thomas H. Lee. "Addressing the Challenge of GrayZone Medicine." New England Journal of Medicine 372, no. 3 (2015): 203-205.

Chassin, Mark R. "Explaining geographic variations: the enthusiasm hypothesis." Medical care (1993): YS37-YS44.

Clemens, Jeffrey, and Joshua D. Gottlieb. "Do Physicians' Financial Incentives Affect Medical Treatment and Patient Health?." The American economic review104, no. 4 (2014): 1320.

Cooper, Zack, Stuart V. Craig, Martin Gaynor, and John Van Reenen, 2015. "The Price Ain't Right? Hospital Prices and Health Spending on the Privately Insured," NBER Working Paper No. 21815.

Currie, Janet, and W. Bentley MacLeod, 2008. "First Do No Harm? Tort Reform and Birth Outcomes," Quarterly Journal of Economics 123(2): 795-830.

Dartmouth Atlas, 2013. http://www.dartmouthatlas.org/tools/downloads.aspx

Doyle Jr, Joseph J. "Returns to local-area healthcare spending: evidence from health shocks to patients far from home." American economic journal. Applied economics 3, no. 3 (2011): 221.

Dranove, David, and Paul Wehner, 1994. "Physician-induced demand for childbirths," Journal of Health Economics 13(1) (March): 61-73.

Dresselhaus, Timothy R., John W. Peabody, Jeff Luck, and Dan Bertenthal, 2004. "An Evaluation of Vignettes for Predicting Variation in the Quality of Preventive Care." Journal of General Internal Medicine 19(10): 1013-1018. 
Epstein, Andrew J., and Sean Nicholson, 2009. "The formation and evolution of physician treatment styles: An application to cesarean sections," Journal of Health Economics, 28(6) (December): 1126-1140.

(ESCAPE) Evaluation Study of Congestive Heart Failure and Pulmonary Artery Catheterization Effectiveness: The ESCAPE Trial. JAMA. 2005; 294(13): 1625-1633.

Evans, Spencer C., Michael C. Roberts, Jared W. Keeley, Jennifer B. Blossom, Christina M. Amaro, et al., 2015. "Vignette methodologies for studying clinicians' decision-making: Validity, utility, and application in ICD-11 field studies. International Journal of Clinical and Health Psychology, 2015 (pre-print).

Finkelstein, Amy, Matthew Gentzkow, and Heidi Williams. Sources of geographic variation in health care: Evidence from patient migration. No. w20789. National Bureau of Economic Research, 2014.

Fisher, Elliott S., David E. Wennberg, Terese A. Stukel, Daniel J. Gottlieb, Francis Lee Lucas, et al., 2003, "The implications of regional variations in Medicare spending. Part 2: Health outcomes and satisfaction with care," Ann Intern Med 138, Feb 18, 288-98.

Gogineni, Keerthi, Katherine L. Shuman, Derek Chinn, Nicole B. Gabler, and Ezekiel J. Emanuel. "Patient Demands and Requests for Cancer Tests and Treatments." JAMA Oncology 1, no. 1 (2015): 33-39.

Gottlieb, Daniel J., Weiping Zhou, Yunjie Song, Kathryn Gilman Andrews, Jonathan S. Skinner, and Jason M. Sutherland, 2010, "Prices don't Drive Regional Medicare Spending Variations." Health Affairs 29(3): 537-543.

Gregoratos, Gabriel, Jonathan Abrams, Andrew E. Epstein, Roger A. Freedman, David L. Hayes, Mark A. Hlatky, Richard E. Kerber et al. "ACC/AHA/NASPE 2002 guideline update for implantation of cardiac pacemakers and antiarrhythmia devices - summary article: a report of the American College of Cardiology/American Heart Association Task Force on Practice Guidelines (ACC/AHA/NASPE Committee to Update the 1998 Pacemaker Guidelines)." Journal of the American College of Cardiology 40, no. 9 (2002): 1703-1719.

Grytten, Jostein, and Rune Sørensen. "Practice variation and physician-specific effects." Journal of health economics 22, no. 3 (2003): 403-418.

Haider, Adil H., Janel Sexton, N. Sriram, Lisa A. Cooper, David T. Efron, Sandra Swoboda, Cassandra V. Villegas et al. "Association of unconscious race and social class bias with vignettebased clinical assessments by medical students." JAMA 306, no. 9 (2011): 942-951.

Hunt, Sharon Ann, William T. Abraham, Marshall H. Chin, Arthur M. Feldman, Gary S. Francis, et al., 2005. "ACC/AHA 2005 Guideline Update for the Diagnosis and Management of Chronic Heart Failure in the Adult," Circulation. 2005;112:e154-e235; (September 13). 
Hunt, Sharon Ann, William T. Abraham, Marshall H. Chin, Arthur M. Feldman, Gary S. Francis, et al., 2009. "2009 Focused Update Incorporated Into the ACC/AHA 2005 Guidelines for the Diagnosis and Management of Chronic Heart Failure in the Adult," Circulation 119:e391-e479 (March 26).

Institute of Medicine, Committee on Geographic Variation in Health Care Spending and Promotion of High-Value Care; Board on Health Care Services; Newhouse JP, Garber AM, Graham RP, et al., editors. Variation in Health Care Spending: Target Decision Making, Not Geography. Washington (DC): National Academies Press (US); 2013 Oct 1. Available from: http://www.ncbi.nlm.nih.gov/books/NBK201647/

Jacobson, Mireille, A. James O’Malley, Craig C. Earle, Juliana Pakes, Peter Gaccione and Joseph P. Newhouse, 2006. "Does Reimbursement Influence Chemotherapy Treatment For Cancer Patients?" Health Affairs, 25(2): 437-443.

Keating, Nancy L., Mary Beth Landrum, Haiden A. Huskamp, Elena M. Kouri, Holly G. Prigerson, Deborah Schrag, Paul K. Maciejewski, Mark C. Hornbrook, and David A. Haggstrom, 2016. "Dartmouth Atlas Area-Level Estimates of End-of-Life Expenditures: How Well Do They Reflect Expenditures for Prospectively Identified Advanced Lung Cancer Patients?" Health Services Research. 51(4) (August): 1584-1594

Keeley EC, Boura JA, Grines CL., 2003. "Primary angioplasty versus intravenous thrombolytic therapy for acute myocardial infarction: a quantitative review of 23 randomised trials," Lancet 361:13-20.

Kelley, Amy S., Susan L. Ettner, R. Sean Morrison, Qingling Du, Neil S. Wenger, and Catherine A. Sarkisian. "Determinants of medical expenditures in the last 6 months of life." Annals of internal medicine 154, no. 4 (2011): 235-242.

Levine-Taub, Anna A., Anton Kolotilin, Robert S. Gibbons, Ernst R. Berndt, 2015. "The Diversity of Concentrated Prescribing Behavior: An Application to Antipsychotics," Journal of Health Economics, 40: 26-39.

Lucas, Francis Lee, Andrea E. Siewers, David J. Malenka, and David E. Wennberg, 2008. "Diagnostic-therapeutic cascade revisited. Coronary angiography, coronary artery bypass surgery, and percutaneous coronary intervention in the modern era." Circulation, 118: 27972802.

Lucas, Frances Lee, Brenda E. Sirovich, Patricia M. Gallagher, Andrea E. Siewers, and David E. Wennberg, 2010. "Variation in Cardiologists' Propensity to Test and Treat: Is it Associated with Regional Variation in Utilization?" Circulation : Cardiovascular Quality and Outcomes $3: 253$ 60 .

Mandelblatt Jeanne S., Leigh Anne Faul, Gheorghe Luta, Solomon B. Makgoeng, Claudine Isaacs, et al., 2012. "Patient and physician decision styles and breast cancer chemotherapy use in 
older women: Cancer and Leukemia Group B protocol 369901" Journal of Clinical Oncology July 20;30(21): 2609-14.

Manski, Charles F., 1990. "The Use of Intentions Data to Predict Behavior: A Best Case Analysis," Journal of the American Statistical Association, 85(412): 934-940.

McGuire, Thomas G., 2011, Physician agency and payment for primary medical care, in Sherry Glied, and Peter C. Smith, eds.: The Oxford handbook of health economics (Oxford University Press).

McGuire, Thomas G., Pauly, M., 1991. "Physician response to fee changes with multiple payers.” Journal of Health Economics, 10 (4), 385-410.

Moliter, David, 2016, “The Evolution of Physician Practice Styles: Evidence from Cardiologist Migration,” NBER Working Paper No. 22478 (August).

Pauly, Mark, 1980. Doctors and their workshops: Economic models of physician behavior (University of Chicago Press, Chicago).

Peabody John W., Jeff Luck, Peter Glassman, Sharad Jain, Joyce Hansen, Maureen Spell, and Martin Lee, 2004. "Measuring the quality of physician practice by using clinical vignettes: a prospective validation study," Annals of Internal Medicine Nov 16;141(10):771-80.

Peabody, John W., Jeff Luck, Peter Glassman, Timothy R. Dresselhaus, and Martin Lee. "Comparison of vignettes, standardized patients, and chart abstraction: a prospective validation study of 3 methods for measuring quality."JAMA 283, no. 13 (2000): 1715-1722.

Rao, Jaya K., Lynda A. Anderson, Feng-Chang Lin, and Jeffrey P. Laux, 2014. "Completion of Advance Directives among U.S. Consumers," American Journal of Preventive Medicine 46(1): 65-70.

Ransohoff, David F., Mary McNaughton Collins, and Floyd J. Fowler Jr., 2002. "Why is prostate cancer screening so common when the evidence is so uncertain? A system without negative feedback," The American Journal of Medicine 113(8): 663-67.

Ryan, Thomas J., Jeffrey L. Anderson, Elliott M. Antman, Blaine A. Braniff, Neil H. Brooks, et al., 1996, "ACC/AHA Guidelines for the Management of Patients With Acute Myocardial Infarction: A Report of the American College of Cardiology/American Heart Association Task Force on Practice Guidelines (Committee on Management of Acute Myocardial Infarction)," Circulation 94:2341-50.

Sheiner, Louise, 2014 Why the Geographic Variation in Health Care Spending Cannot Tell Us Much about the Efficiency or Quality of our Health Care System," Brookings Papers on Economic Activity, 2014(2):1-72. 
Sirovich, Brenda, Patricia M. Gallagher, David E. Wennberg, and Elliott S. Fisher, 2008. "Discretionary Decision Making by Primary Care Physicians and the Cost of U.S. Health Care," Health Affairs 27, May-Jun, 813-23.

Skinner, Jonathan, 2012. "Causes and Consequences of Geographic Variation in Health Care" in Thomas G. McGuire, Mark Pauly, and Pedro P. Barros (eds.) Handbook of Health Economics Vol. 2, North Holland.

Skinner, Jonathan, and Douglas Staiger, 2007, "Technological Diffusion from Hybrid Corn to Beta Blockers" in E. Berndt and C. M. Hulten (eds.) Hard-to-Measure Goods and Services: Essays in Honor of Zvi Griliches. University of Chicago Press and NBER.

Song, Yunjie, Jonathan Skinner, Julie Bynum, Jason Sutherland, John E. Wennberg, and Elliott S. Fisher, 2010. "Regional Variations in Diagnostic Practices," New England Journal of Medicine 363(1): 45-53.

U.S. Department of Health and Human Services, 2004. Seventh Report of the Joint National Committee on Prevention, Detection, Evaluation, and Treatment of High Blood Pressure (JNC7). NIH Publication No. 04-5230.

Wennberg, John E., Benjamin A. Barnes and Michael Zubkoff, 1982. "Professional Uncertainty and the Problem of Supplier-Induced Demand," Social Science and Medicine 16(7): 811-824.

Wennberg, David E., John D. Dickens, Jr., Lois Biener, Floyd J. Fowler, Jr., David N. Soule, and Robert B. Keller, 1997. "Do Physicians Do What they Say? The Inclination to Test and Its Association with Coronary Angiography Rates." Journal of General Internal Medicine 12(3):172-176. 
Figure 1: Theoretical Model of Equilibrium Health Care Intensity (x)

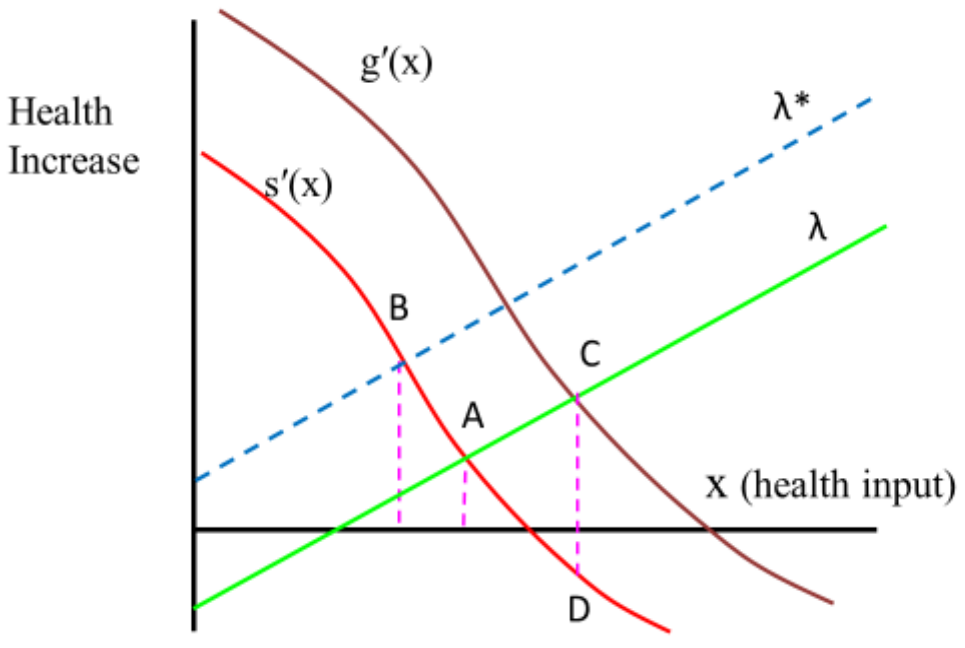


Figure 2: Distributions of Patient Preferences vs. Simulated Distributions (based on 1000 bootstrap samples with replacement)
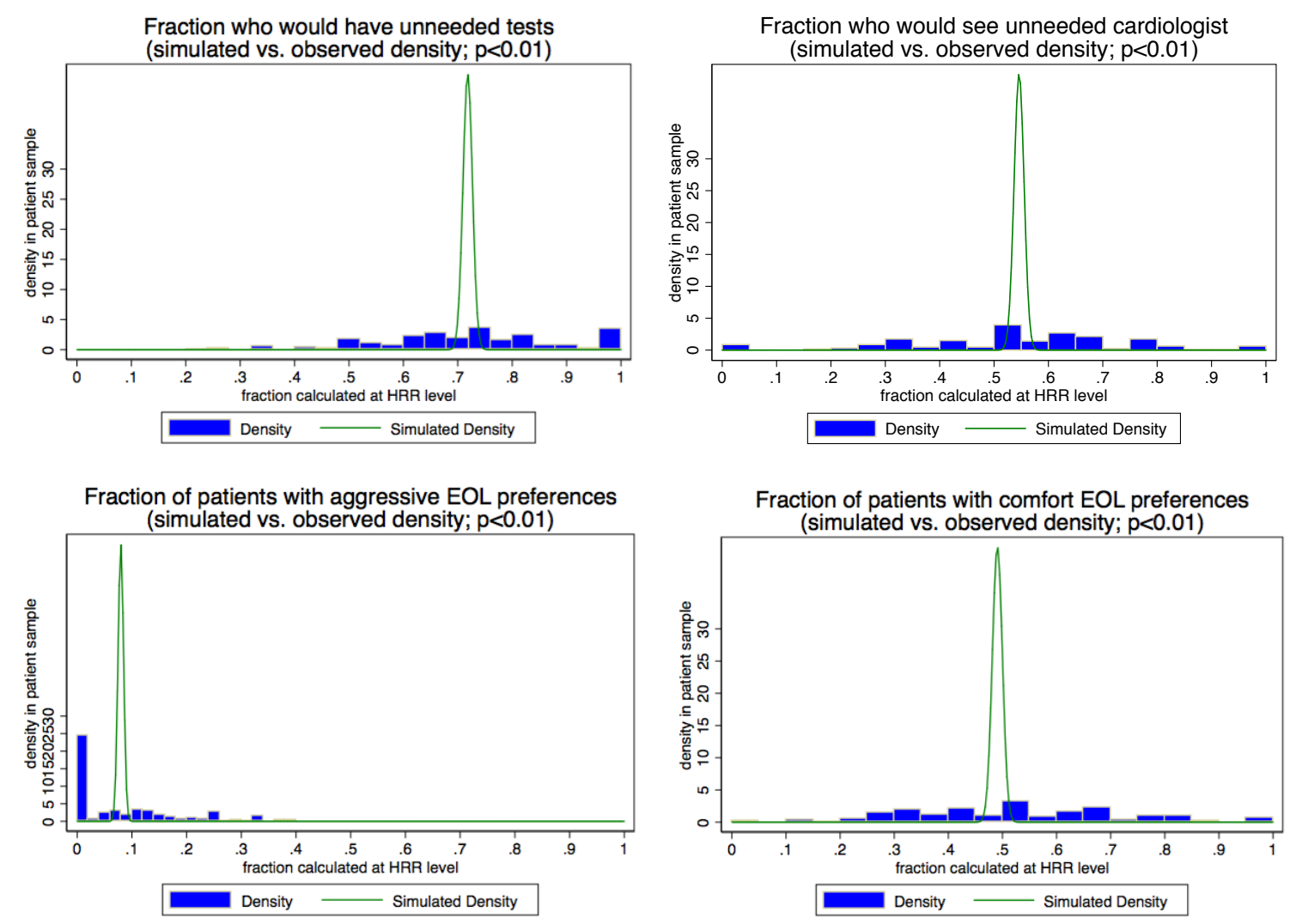
Figure 3a: Distribution of Length of Time before Next Visit for Patient with WellControlled Angina (Cardiologist HRR-Level Averages)

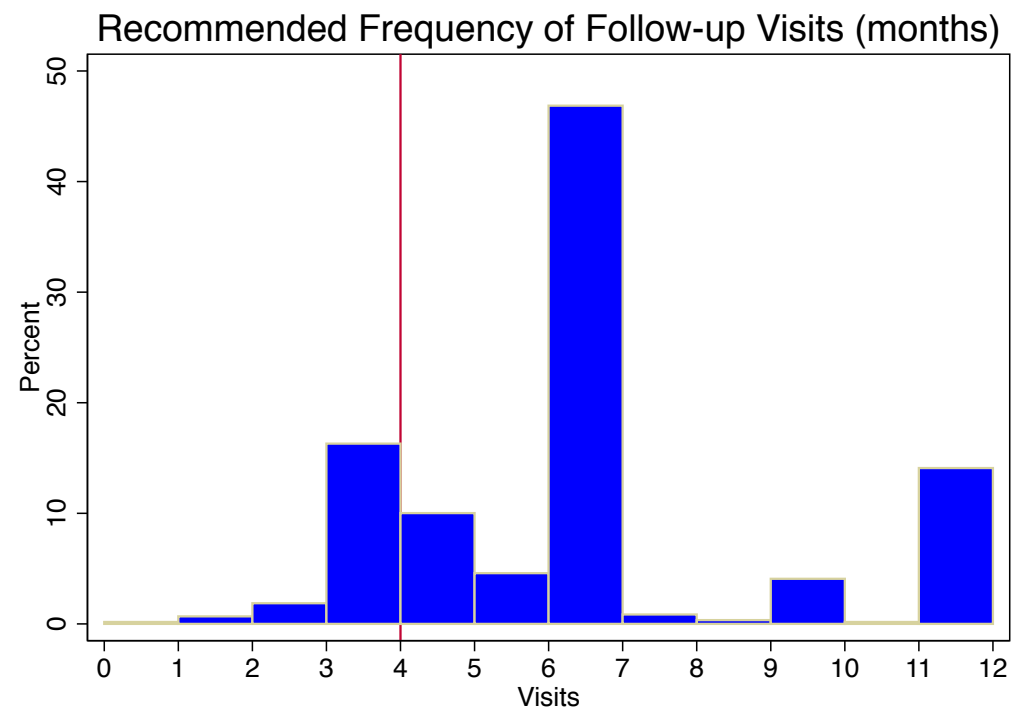

Figure 3b: Distribution of High Follow-Up Cardiologists and Geographic Correlation (HRR-Level Averages)

Fraction high follow-up cardiologists (simulated vs. observed density; $p<0.01$ )

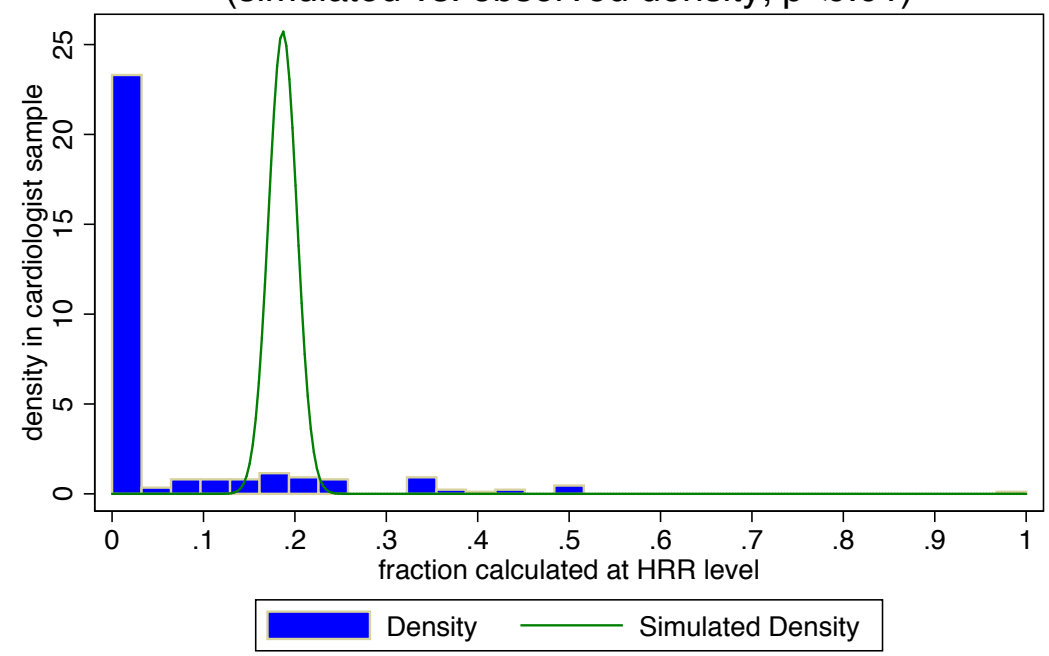


Figure 4: Ln of 2-year End-of-Life Regional Spending vs. Selected Independent Variables

(a) Cowboy Fraction \& Ln 2-year EOL Spend

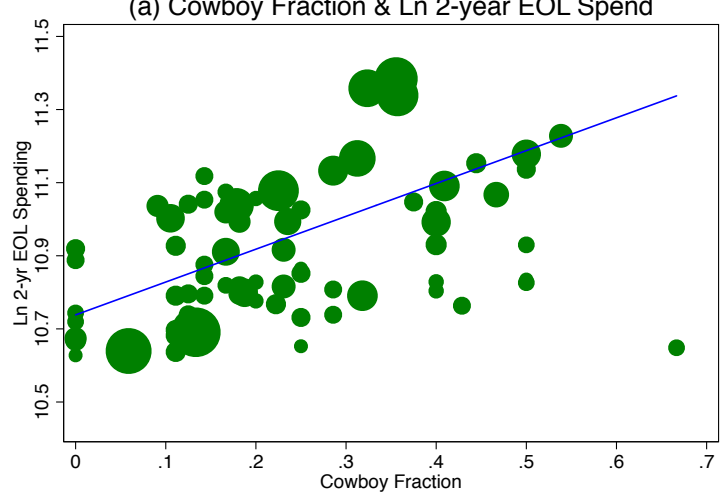

(c) High Follow-Up Fraction \& Ln 2-year EOL Spend

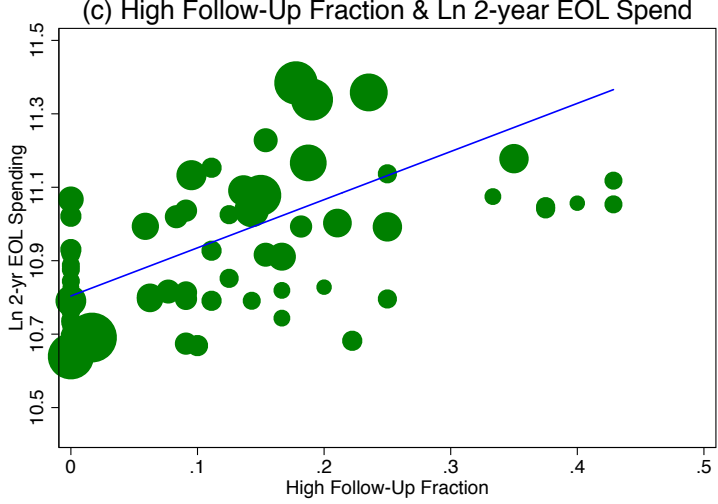

(b) Comforter Fraction \& Ln 2-year EOL Spend

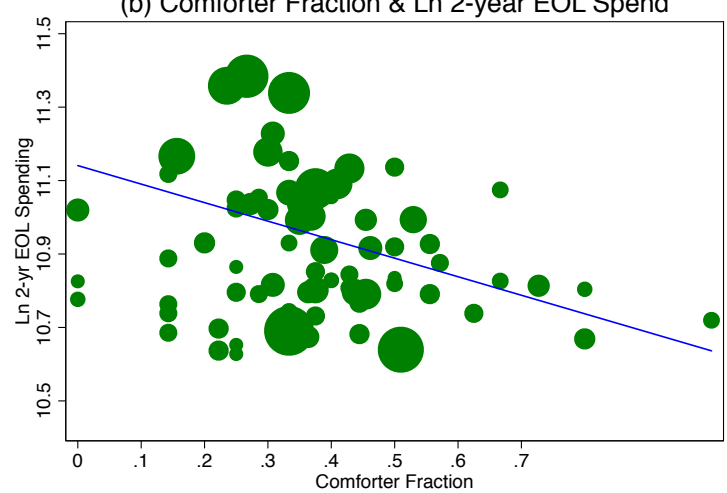

(c) Aggressive Patient Fraction \& Ln 2-year EOL Spend

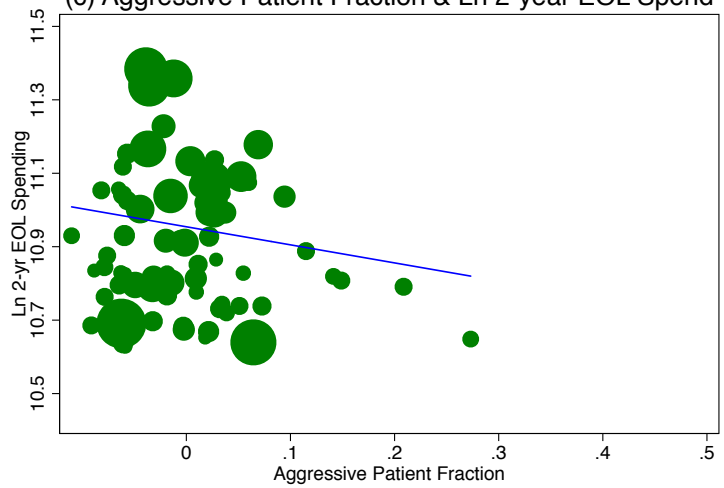




\section{Appendix A: A Model of Variation in Utilization}

We develop a simple model of patient demand and physician supply. The demand side of the model is a standard one; the patient's indirect utility function is a function of out-of-pocket prices $(p)$, income $(Y)$, health $(h)$, and preferences for care $(\eta) ; V=V(p, Y, h, \eta)$. Solving this for optimal intensity of care, $\mathrm{x}$, yields $\mathrm{x}^{\mathrm{D}}$.

On the supply side, we assume that physicians seek to maximize the perceived health of their patient, $s(x)$, by appropriate choice of inputs $x$, subject to patient demand $\left(x^{D}\right)$, financial considerations, and organizational factors.

Following Chandra and Skinner (2012), we write the physician's overall utility as:

(A.1) $U=\Psi_{S}(x)+\Omega(W+\pi x-R)-\phi\left(\left|x-x^{D}\right|\right)-\varphi\left(\left|x-x^{O}\right|\right)$

where $\Psi$ is perceived social value of improving health, $\Omega$ is the physician's utility function of own income, comprising her fixed payment W (a salary, for example) net of fixed costs $\mathrm{R}$, and including the incremental "profits" from each additional test or procedure performed, $\pi .{ }^{30}$ The sign of $\pi$ depends on the type of procedure and the payment system a physician faces.

The third term represents the loss in provider utility arising from the deviation between the quantity of services the provider actually recommends $(\mathrm{x})$ and what the informed patient demands $\left(\mathrm{x}^{\mathrm{D}}\right)$. This function could reflect classic supplier-induced demand - from the physician's point of view, $\mathrm{x}^{\mathrm{D}}$ is too low relative to the physician's optimal $\mathrm{x}$ - or it may reflect the extent to which physicians are acting as the agent of the (possibly misinformed) patient, for example when the patient wants a procedure that the physician does not believe is medically appropriate. The fourth term reflects a parallel influence on physician decision-making exerted

\footnotetext{
${ }^{30}$ We ignore capacity constraints, such as the supply of hospital or ICU beds.
} 
by organizational factors that do not directly affect financial rewards, such as (physician) peer pressure.

The first-order condition for (1) is:

(A.2) $\Psi s^{\prime}(x)=-\Omega^{\prime} \pi+\phi^{\prime}+\varphi^{\prime} \equiv \lambda$

Physicians provide care up to the point where the choice of $\mathrm{x}$ reflects a balance between the perceived marginal value of health, $\Psi \mathrm{s}^{\prime}(\mathrm{x})$, and factors summarized by $\lambda$ : (a) the incremental change in net income $\pi$, weighted by the importance of financial resources $\Omega^{\prime}$, (b) the incremental disutility from moving patient demand away from where it was originally, $\phi^{\prime}$, and (c) the incremental disutility from how much the physician's own choice of $\mathrm{x}$ deviates from her organization's perceived optimal level of intervention, $\varphi^{\prime}$.

In this model, ${ }^{31}$ there are two ways to define "supplier-induced demand." The broadest definition is simply the presence of any equilibrium quantity of care beyond the level of the ex ante preferences of an informed patient, i.e. $x>x^{D}$. This is still relatively benign, as the marginal value of this care may still be positive. Supplier-induced demand could more narrowly be defined as $\mathrm{s}(\mathrm{x})-\mathrm{s}\left(\mathrm{x}^{\mathrm{D}}\right) \leq 0$; for additional care provided at the margin, patients gain no improvement in health outcomes and may even experience a decline in health or a significant financial loss. Importantly, both of these definitions are ambiguous about the question of physician knowledge of inducement beyond clinically appropriate levels. That is, a physician with strong (but incorrect) beliefs may over-treat her patients, even in the absence of financial or organizational incentives to do so.

\footnotetext{
${ }^{31}$ A more general model would account for the patient's ability to leave the physician and seek care from a different physician, as in McGuire (2011).
} 
To develop an empirical model, we adopt a simple closed-form solution of the utility function for physician $\mathrm{i}^{32}$

$$
U_{i}=\Psi s_{i}\left(x_{i}\right)+\omega\left[W_{i}+\pi_{i} x_{i}-R_{i}\right]-\frac{\phi}{2}\left(x_{i}-x_{i}^{D}\right)^{2}-\frac{\varphi}{2}\left(x_{i}-x_{i}{ }^{o}\right)^{2}
$$

Note that $\omega / \Psi$ reflects the relative tradeoff between the physician's income and the value of improving patient lives, and thus might be viewed as a measure of "professionalism," as in Campbell, et al. (2010). The first-order condition is therefore:

(A.2') $s_{i}^{\prime}\left(x_{i}\right)=\lambda \equiv\left(-\omega \pi_{i}+\phi\left(x_{i}-x_{i}^{D}\right)+\varphi\left(x-x_{i}^{o}\right)\right) / \Psi$

Note that $\lambda$ is linear in $\mathrm{x}$ with an intercept equal to $-\left(\omega \pi_{i}+\phi x_{i}{ }^{D}+\varphi x_{i}{ }^{O}\right) / \Psi$. Note also the key assumption that patients are sorted in order from most appropriate to least appropriate for treatment, thus describing a downward sloping $\mathrm{s}^{\prime}(\mathrm{x})$ (marginal utility of treatment) curve. The equilibrium is where $\mathrm{s}^{\prime}(\mathrm{x})=\lambda$, at point $\mathrm{A}$. A shift in the intercept, which depends on reimbursement rates for procedures $\pi$, taste for income $\omega$, regional demand $\mathrm{x}^{\mathrm{D}}$, and organizational or peer effects $\mathrm{x}^{\mathrm{O}}$, would yield a different $\lambda^{*}$, and hence a different utilization rate. However, all of these factors affect the intensity of treatments via a movement along the marginal benefit curve, $\mathrm{s}^{\prime}(\mathrm{x})$.

Alternatively, it may be that $\mathrm{s}_{\mathrm{i}}{ }^{\prime}(\mathrm{x})$ differs across physicians - i.e. physician productivity differs, rather than physician constraints. For example, if $\mathrm{g}_{\mathrm{i}}{ }^{\prime}(\mathrm{x})=\alpha_{\mathrm{i}}+\mathrm{s}^{\prime}(\mathrm{x})$, where $\mathrm{s}^{\prime}(\mathrm{x})$ is average physician productivity and $\alpha$ varies across regions, this would be represented as a shift in the marginal benefit curve. Point $\mathrm{C}$ in Figure I corresponds to greater intensity of care than point A and arises naturally when the physician is or just believes she is more productive. For example, heart attack patients experience better outcomes from cardiac interventions in regions with higher rates of revascularization, consistent with a Roy model of occupational sorting (Chandra

${ }^{32}$ We are grateful to Pascal St.-Amour for suggesting this approach. 
and Staiger, 2007). Because patients in regions with high intervention rates benefit differentially from these interventions, this scenario does not correspond to the narrow definition of "supplierinduced demand."

The productivity shifter $\alpha_{i}$ may also vary because of "professional uncertainty" - a situation in which the physician's perceived $\alpha_{i}$ differs from the true $\alpha_{i}$ (Wennberg, et al., 1982). Physicians may be overly optimistic with respect to their ability to perform procedures, leading to expected benefits that exceed actual realized benefits, as noted in the main text. For example, suppose the actual benefit is $\mathrm{s}^{\prime}(\mathrm{x})$ but the physician's perceived benefit is $\mathrm{g}^{\prime}(\mathrm{x})$. The equilibrium is point $\mathrm{D}$ : the marginal treatment harms the patient, even though the physician believes the opposite, incorrectly believing they are at point C. In equilibrium, this supplier behavior would appear consistent with classic supplier-induced demand, but the cause is quite different.

Empirical Specification. To examine these theories empirically, we consider variation in practice at the regional level (for reasons explained below) but adjusting for health status, $\mathrm{h}$. Taking a first-order Taylor-series approximation of equation (A.2') for region i yields a linear equation that groups equilibrium outcomes into two components, demand factors $Z^{D}$ and supply factors $Z^{S}$ :

(A.4) $x_{i}=\bar{x}+Z_{i}^{D}+Z_{i}^{S}+\varepsilon_{i}$

The demand-side component is:

(A.5) $Z_{i}^{D}=\frac{\phi}{\mathrm{M}}\left(x_{i}^{D}-\bar{x}^{D}\right)$

where $M=-\Psi s^{\prime \prime}(\bar{x})+\phi+\varphi$. This first element of equation (5) reflects the higher average demand for health care, multiplied by the extent to which physicians accommodate that demand, $\phi$. The supply side component is:

(A.6) $Z_{i}^{S}=\frac{1}{M}\left\{\omega \Delta \pi_{i}+\pi \Delta \omega_{i}+\varphi\left(x_{i}{ }^{O}-\bar{x}^{O}\right)+\Psi \Delta \alpha_{i}\right\}$ 
The first term in equation (A.6) reflects how the difference in profits in region $\mathrm{i}$ vs. the national average $(\Delta \pi)$ affects utilization. The second term reflects the extent to which physicians weigh income more heavily. The third term captures organizational goals in region i relative to national averages $\left(x_{i}{ }^{O}-\bar{x}^{O}\right)$. The final term captures the impact of different physician beliefs about productivity of the treatment $\left(\Delta \alpha_{i}\right)$; this term shifts the marginal productivity curve.

Equation (A.4) can be expanded to capture varying parameter values as well. For example, in some regions, physicians may be more responsive to patient demand (a larger $\phi_{\mathrm{i}}$ ). Such interaction effects, considered below, would reflect the interaction of supply and demand and would magnify the responses here. 
Table 1: Primary Variables and Sample Distribution

\begin{tabular}{|c|c|c|c|c|}
\hline Variable & Mean & Individ. SD & Area Av. SD & P-value \\
\hline \multicolumn{5}{|l|}{ Spending and Utilization } \\
\hline 2-Year End-of-Life Spending & $\$ 55,194$ & - & $\$ 10,634$ & - \\
\hline Total Per (AMI) Patient Spending & $\$ 7,551$ & - & $\$ 1,082$ & - \\
\hline Hip Fracture Patient Spending & $\$ 50,685$ & - & $\$ 5,564$ & - \\
\hline \multicolumn{5}{|l|}{ Patient Variables $(\mathrm{N}=1516)$} \\
\hline Have Unneeded Tests & $73 \%$ & $45 \%$ & $12 \%$ & $<0.01$ \\
\hline See Unneeded Cardiologist & $56 \%$ & $50 \%$ & $13 \%$ & $<0.01$ \\
\hline Aggressive Patient Preferences Ratio & $8 \%$ & $27 \%$ & $7 \%$ & $<0.01$ \\
\hline Comfort Patient Preferences Ratio & $48 \%$ & $50 \%$ & $13 \%$ & $<0.01$ \\
\hline \multicolumn{5}{|l|}{ Primary Care Physician Variables $(\mathrm{N}=967)$} \\
\hline Cowboy & $22 \%$ & $41 \%$ & $26 \%$ & $<0.01$ \\
\hline Comforter & $47 \%$ & $50 \%$ & $28 \%$ & $<0.01$ \\
\hline Follow-Up Low & $10 \%$ & $29 \%$ & $19 \%$ & $<0.01$ \\
\hline Follow-Up High & $3 \%$ & $17 \%$ & $6 \%$ & $<0.01$ \\
\hline \multicolumn{5}{|l|}{ Cardiologist variables $(\mathrm{N}=598)$} \\
\hline Cowboy & $25 \%$ & $43 \%$ & $20 \%$ & $<0.01$ \\
\hline Comforter & $27 \%$ & $44 \%$ & $23 \%$ & $<0.01$ \\
\hline Follow-Up Low & $2 \%$ & $12 \%$ & $7 \%$ & - \\
\hline Follow-Up High & $19 \%$ & $39 \%$ & $22 \%$ & $<0.01$ \\
\hline \multicolumn{5}{|l|}{ All Physicians $(\mathrm{N}=1565)$} \\
\hline Cowboy & $23 \%$ & $42 \%$ & $15 \%$ & $<0.01$ \\
\hline Comforter & $39 \%$ & $49 \%$ & $18 \%$ & $<0.01$ \\
\hline Follow-Up Low & $6 \%$ & $25 \%$ & $8 \%$ & $<0.01$ \\
\hline Follow-Up High & $9 \%$ & $29 \%$ & $12 \%$ & $<0.01$ \\
\hline \multicolumn{5}{|l|}{ Organizational and Financial Variables $(\mathrm{N}=1533)$} \\
\hline \multicolumn{5}{|l|}{ Reimbursement } \\
\hline Fraction Medicare Patients & $42 \%$ & $22 \%$ & - & - \\
\hline Fraction Medicaid Patients & $10 \%$ & $13 \%$ & - & - \\
\hline Fraction Capitated Patients & $15 \%$ & $25 \%$ & - & - \\
\hline \multicolumn{5}{|l|}{ Organizational Factors } \\
\hline Solo or 2-person Practice & $29 \%$ & $46 \%$ & - & - \\
\hline Single/Multi Speciality Group Practice & $57 \%$ & $50 \%$ & - & - \\
\hline Group/Staff HMO or Hospital-Based Practice & $13 \%$ & $33 \%$ & - & - \\
\hline \multicolumn{5}{|l|}{ General Controls } \\
\hline Physician Age & 53 & 10 & - & - \\
\hline Male & $81 \%$ & $39 \%$ & - & - \\
\hline Board Certified & $88 \%$ & $33 \%$ & - & - \\
\hline Weekly Patient Days & 2.9 & 1.5 & - & - \\
\hline Cardiologists per $100 \mathrm{k}(\mathrm{N}=74, \mathrm{HRR}-\mathrm{level})$ & 6.8 & 1.9 & - & - \\
\hline \multicolumn{5}{|l|}{ Responsiveness Factors } \\
\hline Responds to Referrer Expectations (Cardiologists only) & $31 \%$ & $46 \%$ & - & - \\
\hline Responds to Colleague Expectations & $38 \%$ & $49 \%$ & - & - \\
\hline Responds to Patient Expectations & $54 \%$ & $50 \%$ & - & - \\
\hline Responds to Malpractice Concerns & $39 \%$ & $49 \%$ & - & - \\
\hline Responds to Practice Financial Incentives & $9 \%$ & $29 \%$ & - & - \\
\hline \multicolumn{5}{|c|}{$\begin{array}{l}\text { Note: The table shows means for the primary analysis sample. The p-value in the last column is for the nul } \\
\text { hypothesis of no excess variance across areas and is taken from a bootstrap of patient or physician responses across } \\
\text { areas. For each of } 1,000 \text { simulations, we draw patients or providers randomly (with replacement) and calculate the } \\
\text { simulated area average and the standard deviation of that area average. The empirical distribution of the standard } \\
\text { deviation of the area average is used to form the p-value for the actual area average. }\end{array}$} \\
\hline
\end{tabular}


Table 2: Distribution of Physicians by Vignette Responses

\begin{tabular}{|c|c|c|c|c|c|c|}
\hline \multicolumn{6}{|c|}{ Panel A: PCPs } & \multirow{7}{*}{$\begin{array}{l}10 \% \\
87 \% \\
3 \%\end{array}$} \\
\hline & \multicolumn{3}{|c|}{ Cowboy } & \multicolumn{2}{|c|}{ Comforter } & \\
\hline Follow-Up Frequency & No & Yes & & No & Yes & \\
\hline Low & 75 & 17 & & 53 & 39 & \\
\hline Medium & 663 & 182 & & 436 & 409 & \\
\hline \multirow[t]{2}{*}{ High } & 16 & 14 & & 19 & 11 & \\
\hline & $78 \%$ & $22 \%$ & & $53 \%$ & $47 \%$ & \\
\hline \multirow[t]{2}{*}{$p\left(\chi^{2}\right):$} & $<0.0$ & & & $p\left(\chi^{2}\right):$ & 0.28 & \\
\hline & \multicolumn{3}{|c|}{ Comforter } & & & \\
\hline Cowboy & No & Yes & & & & \\
\hline No & 383 & 371 & $78 \%$ & & & \\
\hline \multirow[t]{2}{*}{ Yes } & 125 & 88 & $22 \%$ & & & \\
\hline & $53 \%$ & $47 \%$ & & & & \\
\hline$p\left(\chi^{2}\right):$ & 0.06 & & & & & \\
\hline \multicolumn{7}{|c|}{ Panel B: Cardiologists } \\
\hline & \multicolumn{3}{|c|}{ Cowboy } & \multicolumn{2}{|c|}{ Comforter } & \\
\hline Follow-Up Frequency & No & Yes & & No & Yes & \\
\hline Low & 8 & 1 & $2 \%$ & 8 & 1 & $2 \%$ \\
\hline Medium & 360 & 117 & $80 \%$ & 343 & 134 & $80 \%$ \\
\hline \multirow[t]{2}{*}{ High } & 80 & 32 & $19 \%$ & 88 & 24 & $19 \%$ \\
\hline & $87 \%$ & $29 \%$ & & $85 \%$ & $72 \%$ & \\
\hline \multirow[t]{2}{*}{$p\left(\chi^{2}\right):$} & $<0.0$ & & & $p\left(\chi^{2}\right):$ & $<0.01$ & \\
\hline & \multicolumn{3}{|c|}{ Comforter } & & & \\
\hline Cowboy & No & Yes & & & & \\
\hline No & 334 & 114 & $75 \%$ & & & \\
\hline \multirow[t]{2}{*}{ Yes } & 105 & 45 & $25 \%$ & & & \\
\hline & $73 \%$ & $27 \%$ & & & & \\
\hline$p\left(\chi^{2}\right):$ & \multicolumn{5}{|c|}{$<0.01$} & \\
\hline \multicolumn{7}{|c|}{$\begin{array}{l}\text { This table shows the bivariate relationships between the guideline-defined indica- } \\
\text { torsfor recommended Follow-Up Frequency, as well as "Cowboy" and "Comforter" } \\
\text { status among both PCPs and Cardiologists in our data. Chi-squared tests evaluate } \\
\text { the null that there is no association between pairs of indicators in the table. }\end{array}$} \\
\hline
\end{tabular}

Table 3: Regression Estimates of Ln Medicare Expenditures in the Last Two Years of Life

\begin{tabular}{|c|c|c|c|c|c|c|c|}
\hline \multicolumn{8}{|c|}{ Combined sample: PCPs and cardiologists } \\
\hline & (1) & (2) & (3) & (4) & (5) & (6) & (7) \\
\hline Cowboy physician share & $\begin{array}{c}0.830^{* * *} \\
(0.202)\end{array}$ & $\begin{array}{c}0.697^{* * *} \\
(0.147)\end{array}$ & $\begin{array}{c}0.713^{* * *} \\
(0.136)\end{array}$ & $\begin{array}{c}0.704^{* * *} \\
(0.137)\end{array}$ & $\begin{array}{c}0.721^{* * *} \\
(0.128)\end{array}$ & & $\begin{array}{c}0.960^{* * *} \\
(0.195)\end{array}$ \\
\hline Comforter physician share & $\begin{array}{c}-0.317^{*} \\
(0.144)\end{array}$ & $\begin{array}{l}-0.200 \\
(0.101)\end{array}$ & $\begin{array}{l}-0.183 \\
(0.102)\end{array}$ & $\begin{array}{l}-0.154 \\
(0.103)\end{array}$ & $\begin{array}{l}-0.146 \\
(0.099)\end{array}$ & & $\begin{array}{l}-0.244 \\
(0.136)\end{array}$ \\
\hline High follow-up physician share & & $\begin{array}{c}1.085^{* * *} \\
(0.178)\end{array}$ & $\begin{array}{c}1.005 * * * \\
(0.176)\end{array}$ & $\begin{array}{c}1.080^{* * *} * \\
(0.171)\end{array}$ & $\begin{array}{c}0.996^{* * *} * \\
(0.171)\end{array}$ & & $\begin{array}{c}1.184^{* * *} * \\
(0.229)\end{array}$ \\
\hline Low follow-up physician share & & $\begin{array}{c}-0.355 \\
(0.225)\end{array}$ & $\begin{array}{l}-0.345 \\
(0.227)\end{array}$ & $\begin{array}{c}-0.479 \\
(0.276)\end{array}$ & $\begin{array}{c}-0.444 \\
(0.268)\end{array}$ & & $\begin{array}{c}-0.808^{*} \\
(0.360)\end{array}$ \\
\hline Have unneeded tests patient share & & & $\begin{array}{c}0.308 \\
(0.180)\end{array}$ & & $\begin{array}{c}0.308 \\
(0.196)\end{array}$ & $\begin{array}{c}0.353 \\
(0.262)\end{array}$ & $\begin{array}{c}0.353 \\
(0.247)\end{array}$ \\
\hline See unneeded cardiologist patient share & & & $\begin{array}{c}0.087 \\
(0.137)\end{array}$ & & $\begin{array}{c}0.099 \\
(0.136)\end{array}$ & $\begin{array}{c}0.498 \\
(0.265)\end{array}$ & $\begin{array}{c}-0.114 \\
(0.170)\end{array}$ \\
\hline Aggressive patient preferences share & & & & $\begin{array}{c}-0.469 \\
(0.430)\end{array}$ & $\begin{array}{c}-0.367 \\
(0.417)\end{array}$ & $\begin{array}{c}-0.203 \\
(0.600)\end{array}$ & $\begin{array}{c}-0.872 \\
(0.537)\end{array}$ \\
\hline Comfort patient preferences share & & & & $\begin{array}{c}-0.095 \\
(0.148)\end{array}$ & $\begin{array}{c}-0.174 \\
(0.174)\end{array}$ & $\begin{array}{l}-0.156 \\
(0.217)\end{array}$ & $\begin{array}{c}-0.514^{* *} \\
(0.182)\end{array}$ \\
\hline $\mathrm{N}$ & 74 & 74 & 74 & 74 & 74 & 74 & 74 \\
\hline$R^{2}$ & 0.341 & 0.616 & 0.637 & 0.626 & 0.646 & 0.117 & 0.599 \\
\hline $\begin{array}{l}{ }^{*} \mathrm{p}<0.05,{ }^{* *} \mathrm{p}<0.01,{ }^{* * *} \mathrm{p}<0.001 \\
2-\text { year End-of-Life Spending is in natura } \\
\text { Referral Regions (HRRs) in which we } \\
\text { regressions include a constant, control } \\
\text { for } \% \text { black and } \% \text { poverty at the HRR } \\
\text { into account differences in the number }\end{array}$ & form a & s price, & sex and & $\begin{array}{l}\text { adjust } \\
\text { e phys } \\
\text { ns in } t\end{array}$ & $\begin{array}{c}\text { esults s } \\
\text { and } 3 \\
\text { mple, a } \\
\text { age. S }\end{array}$ & $\begin{array}{l}1 \text { are } \\
\text { liolog }\end{array}$ & $\begin{array}{l}74 \text { Hosp } \\
\text { irveyed. } \\
\text { controll } \\
\text { weights t }\end{array}$ \\
\hline
\end{tabular}


Table 4: Regression Results for One-Year Medicare Spending and Quality: Acute Myocardial Infarction Patients, 2007-10

\begin{tabular}{|c|c|c|c|c|c|c|}
\hline & $\begin{array}{c}(1) \\
\text { 1-year Med. } \\
\text { Expenditure }\end{array}$ & $\begin{array}{c}(2) \\
\text { Ln 1-year Med } \\
\text { Expenditure }\end{array}$ & $\begin{array}{c}(3) \\
\text { 1-year Med. } \\
\text { Expenditure }\end{array}$ & $\begin{array}{c}(4) \\
\text { Ln 1-year Med } \\
\text { Expenditure }\end{array}$ & $\begin{array}{c}(5) \\
\text { 1-year survival }\end{array}$ & $\begin{array}{c}(6) \\
\text { Fraction with } \\
\text { Same-Day PCI }\end{array}$ \\
\hline Cowboy physician share & $\begin{array}{c}7718.972^{* * *} \\
(1794.479)\end{array}$ & $\begin{array}{c}0.145^{* * *} \\
(0.035)\end{array}$ & $\begin{array}{c}10729.160^{* * *} \\
(2373.421)\end{array}$ & $\begin{array}{c}0.199^{* * *} \\
(0.044)\end{array}$ & $\begin{array}{c}0.009 \\
(0.008)\end{array}$ & $\begin{array}{c}0.020 \\
(0.019)\end{array}$ \\
\hline Comforter physician share & $\begin{array}{l}-2825.727^{*} \\
(1150.591)\end{array}$ & $\begin{array}{l}-0.049^{*} \\
(0.021)\end{array}$ & $\begin{array}{c}-3138.676^{*} \\
(1436.300)\end{array}$ & $\begin{array}{l}-0.049 \\
(0.025)\end{array}$ & $\begin{array}{c}0.008 \\
(0.007)\end{array}$ & $\begin{array}{l}-0.010 \\
(0.016)\end{array}$ \\
\hline High follow-up physician share & $\begin{array}{c}16602.164^{* * *} \\
(2644.898)\end{array}$ & $\begin{array}{c}0.271^{* * *} \\
(0.048)\end{array}$ & $\begin{array}{c}22578.745^{* * *} \\
(3382.609)\end{array}$ & $\begin{array}{c}0.364^{* * *} \\
(0.053)\end{array}$ & $\begin{array}{l}-0.008 \\
(0.013)\end{array}$ & $\begin{array}{l}-0.062^{*} \\
(0.027)\end{array}$ \\
\hline Low follow-up physician share & $\begin{array}{l}-3566.531 \\
(2964.341)\end{array}$ & $\begin{array}{l}-0.090 \\
(0.057)\end{array}$ & $\begin{array}{l}-4550.780 \\
(3642.750)\end{array}$ & $\begin{array}{l}-0.124^{*} \\
(0.060)\end{array}$ & $\begin{array}{c}0.015 \\
(0.015)\end{array}$ & $\begin{array}{c}0.089^{* *} * \\
(0.033)\end{array}$ \\
\hline HCC (2nd Quintile) & $\begin{array}{c}5301.891 * * * \\
(195.261)\end{array}$ & $\begin{array}{c}0.106^{* * * *} \\
(0.003)\end{array}$ & $\begin{array}{c}5429.471^{* * *} \\
(251.765)\end{array}$ & $\begin{array}{c}0.108^{* * *} \\
(0.004)\end{array}$ & $\begin{array}{c}-0.044^{* * *} \\
(0.002)\end{array}$ & $\begin{array}{c}-0.027^{* * *} \\
(0.002)\end{array}$ \\
\hline HCC (3rd Quintile) & $\begin{array}{c}8544.447^{* * *} \\
(227.781)\end{array}$ & $\begin{array}{c}0.177^{* * *} \\
(0.004)\end{array}$ & $\begin{array}{c}9110.242^{* * *} \\
(352.614)\end{array}$ & $\begin{array}{c}0.187^{* * *} * \\
(0.007)\end{array}$ & $\begin{array}{c}-0.092^{* * *} \\
(0.002)\end{array}$ & $\begin{array}{c}-0.053^{* * *} \\
(0.002)\end{array}$ \\
\hline HCC (4th Quintile) & $\begin{array}{c}11671.690^{* * * *} \\
(285.597)\end{array}$ & $\begin{array}{c}0.243^{* * *} \\
(0.005)\end{array}$ & $\begin{array}{c}12200.277^{* * *} \\
(536.789)\end{array}$ & $\begin{array}{c}0.253^{* * *} * \\
(0.010)\end{array}$ & $\begin{array}{c}-0.149^{* * *} \\
(0.003)\end{array}$ & $\begin{array}{c}-0.084^{* * *} \\
(0.002)\end{array}$ \\
\hline HCC (Highest Quintile) & $\begin{array}{c}19308.930 * * * \\
(510.148)\end{array}$ & $\begin{array}{c}0.347^{* * * *} \\
(0.008)\end{array}$ & $\begin{array}{c}20491.203^{* * *} \\
(937.518)\end{array}$ & $\begin{array}{c}0.366^{* * *} \\
(0.015)\end{array}$ & $\begin{array}{c}-0.258 * * * \\
(0.003)\end{array}$ & $\begin{array}{c}-0.124^{* * *} \\
(0.003)\end{array}$ \\
\hline Black & $\begin{array}{c}4893.714^{* * *} \\
(542.788)\end{array}$ & $\begin{array}{c}0.053^{* * *} \\
(0.009)\end{array}$ & $\begin{array}{c}4623.645^{* * *} \\
(740.112)\end{array}$ & $\begin{array}{c}0.048^{* * *} \\
(0.010)\end{array}$ & $\begin{array}{c}-0.020^{* * *} \\
(0.003)\end{array}$ & $\begin{array}{c}-0.040^{* * *} \\
(0.004)\end{array}$ \\
\hline Hispanic & $\begin{array}{c}5024.834^{* * *} \\
(1148.736)\end{array}$ & $\begin{array}{c}0.080^{* * * *} \\
(0.023)\end{array}$ & $\begin{array}{c}4845.783^{* * *} \\
(1228.219)\end{array}$ & $\begin{array}{c}0.081^{* *} \\
(0.028)\end{array}$ & $\begin{array}{c}0.016^{* * * *} \\
(0.005)\end{array}$ & $\begin{array}{l}-0.006 \\
(0.005)\end{array}$ \\
\hline Asian & $\begin{array}{c}1598.930 \\
(1117.807)\end{array}$ & $\begin{array}{l}-0.006 \\
(0.022)\end{array}$ & $\begin{array}{l}1076.400 \\
(1429.055)\end{array}$ & $\begin{array}{l}-0.013 \\
(0.027)\end{array}$ & $\begin{array}{l}-0.005 \\
(0.007)\end{array}$ & $\begin{array}{c}-0.023^{*} \\
(0.011)\end{array}$ \\
\hline Income (2nd Quintile) & $\begin{array}{l}-242.011 \\
(344.303)\end{array}$ & $\begin{array}{c}-0.007 \\
(0.006)\end{array}$ & $\begin{array}{l}-397.333 \\
(592.359)\end{array}$ & $\begin{array}{c}-0.007 \\
(0.009)\end{array}$ & $\begin{array}{c}0.010^{* * *} * \\
(0.002)\end{array}$ & $\begin{array}{c}0.007 \\
(0.004)\end{array}$ \\
\hline Income (3rd Quintile) & $\begin{array}{c}-290.474 \\
(325.867)\end{array}$ & $\begin{array}{c}-0.009 \\
(0.006)\end{array}$ & $\begin{array}{l}-450.441 \\
(556.754)\end{array}$ & $\begin{array}{l}-0.012 \\
(0.008)\end{array}$ & $\begin{array}{c}0.012^{* * *} \\
(0.002)\end{array}$ & $\begin{array}{c}0.009^{*} \\
(0.004)\end{array}$ \\
\hline Income (4th Quintile) & $\begin{array}{c}163.149 \\
(399.974)\end{array}$ & $\begin{array}{c}-0.002 \\
(0.008)\end{array}$ & $\begin{array}{c}-345.768 \\
(608.204)\end{array}$ & $\begin{array}{c}-0.007 \\
(0.011)\end{array}$ & $\begin{array}{c}0.016^{* * *} \\
(0.002)\end{array}$ & $\begin{array}{c}0.016^{* *} \\
(0.005)\end{array}$ \\
\hline Income (Highest Quintile) & $\begin{array}{c}357.765 \\
(503.921)\end{array}$ & $\begin{array}{l}0.008 \\
(0.009)\end{array}$ & $\begin{array}{l}-640.282 \\
(762.327)\end{array}$ & $\begin{array}{l}-0.006 \\
(0.013)\end{array}$ & $\begin{array}{c}0.029 * * * \\
(0.003)\end{array}$ & $\begin{array}{l}0.019 * * \\
(0.006)\end{array}$ \\
\hline $\begin{array}{l}\mathrm{N} \\
R^{2}\end{array}$ & $\begin{array}{c}560392 \\
0.070\end{array}$ & $\begin{array}{c}560392 \\
0.075\end{array}$ & $\begin{array}{c}560392 \\
0.075\end{array}$ & $\begin{array}{c}560392 \\
0.082\end{array}$ & $\begin{array}{c}560392 \\
-\end{array}$ & $\begin{array}{c}560392 \\
-\end{array}$ \\
\hline $\begin{array}{l}* \mathrm{p}<0.05, * * \mathrm{p}<0.01, * * * \mathrm{p}<0 . \\
\text { Based on a } 100 \% \text { sample of fee } \\
\text { unweighted and columns } 3 \text { and } \\
137 \text { HRRs and risk adjustment } \\
\text { vascular disease, pulmonary dis } \\
\text { and location of the AMI: Anter } \\
\text { site, or not otherwise specified. } \\
\text { coefficients for columns } 5 \text { and } 6\end{array}$ & $\begin{array}{l}\text { r-service Med } \\
\text { are weighted } \\
\text { easures includ } \\
\text { e, dementia, } \\
\text { ateral, inferola } \\
\text { espondent dat }\end{array}$ & $\begin{array}{l}\text { e enrollees, } 2 \\
\text { the number } \\
\text { but not repor } \\
\text { etes, liver fail } \\
\text { l, inferoposte } \\
\text { adjusted for }\end{array}$ & $\begin{array}{l}10 \text { with mort } \\
\text { hysician respo } \\
\text { age }(65-69,7 \\
\text { renal failure, } \\
\text {, all other inf } \\
\text {, sex and age } \\
\text { essions. }\end{array}$ & $\begin{array}{l}\text { y follow-up th } \\
\text { lents included } \\
74,75-79,80-8 \\
\text { ncer, plegia (st } \\
\text { or, true posteri } \\
\text { d all models in }\end{array}$ & $\begin{array}{l}\text { h } 2011 \text {. Colu } \\
\text { he sample. A } \\
\text { 5+), fully inte } \\
\text { ), rheumatolo } \\
\text { valls, or suber } \\
\text { de year fixed }\end{array}$ & $\begin{array}{l}\text { s } 1 \text { and } 2 \text { are } \\
\text { esults are for } \\
\text { cted with sex, } \\
\text { disease, HIV, } \\
\text { cardial, other } \\
\text { cts. Reported }\end{array}$ \\
\hline
\end{tabular}


Table 5: Predictors of Cowboy, comforter \& high follow-up physician types

\begin{tabular}{|c|c|c|c|}
\hline & $\begin{array}{c}(1) \\
\text { Cowboy physician }\end{array}$ & $\begin{array}{c}(2) \\
\text { Comforter physician }\end{array}$ & $\begin{array}{c}(3) \\
\text { High follow-up physician }\end{array}$ \\
\hline \multicolumn{4}{|l|}{ General Controls } \\
\hline Cardiologist dummy & $\begin{array}{c}0.005 \\
(0.042)\end{array}$ & $\begin{array}{l}-0.092 \\
(0.048)\end{array}$ & $\begin{array}{c}0.222^{* * *} \\
(0.029)\end{array}$ \\
\hline Age & $\begin{array}{l}0.003^{*} \\
(0.001)\end{array}$ & $\begin{array}{l}0.000 \\
(0.002)\end{array}$ & $\begin{array}{c}0.004^{* * * *} \\
(0.001)\end{array}$ \\
\hline Male & $\begin{array}{c}0.027 \\
(0.037)\end{array}$ & $\begin{array}{l}-0.072 \\
(0.042)\end{array}$ & $\begin{array}{c}-0.078^{* *} \\
(0.025)\end{array}$ \\
\hline Weekly patient days & $\begin{array}{l}-0.011 \\
(0.009)\end{array}$ & $\begin{array}{l}0.024^{*} \\
(0.011)\end{array}$ & $\begin{array}{c}0.008 \\
(0.006)\end{array}$ \\
\hline Board certified & $\begin{array}{l}-0.033 \\
(0.043) \\
\end{array}$ & $\begin{array}{l}-0.035 \\
(0.049) \\
\end{array}$ & $\begin{array}{c}0.010 \\
(0.030) \\
\end{array}$ \\
\hline \multicolumn{4}{|l|}{ Reimbursement } \\
\hline Fraction capitated patients & $\begin{array}{c}0.001 \\
(0.001)\end{array}$ & $\begin{array}{l}-0.000 \\
(0.001)\end{array}$ & $\begin{array}{c}0.000 \\
(0.000)\end{array}$ \\
\hline Fraction Medicaid patients & $\begin{array}{c}0.004^{* * *} \\
(0.001)\end{array}$ & $\begin{array}{c}0.001 \\
(0.001)\end{array}$ & $\begin{array}{c}0.001 \\
(0.001)\end{array}$ \\
\hline Fraction Medicare patients & $\begin{array}{c}0.001 \\
(0.001)\end{array}$ & $\begin{array}{c}0.000 \\
(0.001) \\
\end{array}$ & $\begin{array}{c}0.000 \\
(0.000) \\
\end{array}$ \\
\hline \multicolumn{4}{|l|}{ Organizational Factors } \\
\hline (Baseline $=$ Solo or 2-person Practice) & - & - & - \\
\hline Single/multi speciality group practice & $\begin{array}{c}-0.101^{* *} \\
(0.032)\end{array}$ & $\begin{array}{l}-0.008 \\
(0.037)\end{array}$ & $\begin{array}{c}-0.164 * * * \\
(0.022)\end{array}$ \\
\hline Group/staff HMO or hospital-based practice & $\begin{array}{c}-0.171^{* * *} \\
(0.047)\end{array}$ & $\begin{array}{c}0.038 \\
(0.053) \\
\end{array}$ & $\begin{array}{c}-0.153^{* * * *} \\
(0.032)\end{array}$ \\
\hline \multicolumn{4}{|l|}{ Responsiveness Factors } \\
\hline Responds to patient expectations & $\begin{array}{l}-0.036 \\
(0.036)\end{array}$ & $\begin{array}{c}0.047 \\
(0.041)\end{array}$ & $\begin{array}{l}-0.007 \\
(0.025)\end{array}$ \\
\hline Responds to colleague expectations & $\begin{array}{l}-0.015 \\
(0.030)\end{array}$ & $\begin{array}{l}-0.005 \\
(0.035)\end{array}$ & $\begin{array}{c}0.026 \\
(0.021)\end{array}$ \\
\hline Responds to referrer expectations & $\begin{array}{l}0.061 \\
(0.046)\end{array}$ & $\begin{array}{l}-0.022 \\
(0.053)\end{array}$ & $\begin{array}{l}-0.033 \\
(0.032)\end{array}$ \\
\hline Responds to malpractice concerns & $\begin{array}{c}0.041 \\
(0.030) \\
\end{array}$ & $\begin{array}{c}0.045 \\
(0.034) \\
\end{array}$ & $\begin{array}{c}0.006 \\
(0.021) \\
\end{array}$ \\
\hline $\mathrm{N}$ & 978 & 978 & 978 \\
\hline$R^{2}$ (within) & 0.048 & 0.046 & 0.150 \\
\hline$R^{2}$ (between) & 0.075 & 0.009 & 0.117 \\
\hline$R^{2}$ (overall) & 0.059 & 0.040 & 0.157 \\
\hline \multicolumn{4}{|c|}{$\begin{array}{l}* \mathrm{p}<0.05,{ }^{*} \mathrm{p}<0.01,{ }^{* *} \mathrm{p}<0.001 \\
\text { All logit regressions include a constant, and HRR-level random effects as well as general physician-level controls. } \\
\text { Additional explanatory variables include financial, organizational and responsiveness factors. Results shown are } \\
\text { for the } 74 \text { Hospital Referral Regions (HRRs) in which we have at least } 3 \text { patients, } 1 \text { primary care physician, and } \\
3 \text { cardiologists surveyed. The question on responding to referring doctor expectations appeared in the cardiologist } \\
\text { survey only, and so reflects the preferences of cardiologists only; the cardiology dummy variable therefore reflects } \\
\text { both the pure effect of being a practicing cardiologist, and a secondary adjustment arising from the referral ques- } \\
\text { tion being set to zero for all primary care physicians. All results are robust to including a measure of capacity } \\
\text { (cardiologists per 100k Medicare beneficiaries) among the explanatory variables. }\end{array}$} \\
\hline
\end{tabular}




\title{
Appendix B: Survey Questions and Definitions
}

\author{
Clinical Vignettes and Response Options
}

\section{Panel I: Patient Questions}

SCENARIO 1- Questions relating to less-severe cardiac care preferences: Suppose you noticed a mild but definite chest pain when walking up stairs...S Suppose you went to your regular doctor for that chest pain and your doctor did not think you needed any special tests but you could have some tests if you wanted.

a) If the tests did not have any health risks, do you think you would probably have the tests or probably not have them?

a - have tests

b - not have tests

b) Suppose your doctor told you he or she did not think you needed to see a heart specialist, but you could see one if you wanted. Do you think you would probably ask to see a specialist, or probably not see a specialist?

a - see specialist

b - not see specialist

SCENARIO 2 - Questions relating to end of life care preferences: The next set of questions are about care a patient may receive during the last months of life. Remember, you can skip any question you don't want to answer. Suppose that you had a very serious illness. Imagine that no one knew exactly how long you would live, but your doctors said you almost certainly would live less than 1 year.

a) If you reached the point at which you were feeling bad all the time, would you want drugs that would make you feel better, even if they might shorten your life?

a - yes: drugs

$\mathrm{b}-$ no

b1) If you needed a respirator to stay alive, and it would extend your life for a week, would you want to be put on a respirator?

b2) If it would extend your life for a month, would you want to be put on a respirator?

a - yes: respirator

$\mathrm{b}-$ no

Answers other than "yes" or "no" (e.g., "not concerned" or "I dont know") are treated as missing data. Item non-response was less than $1 \%$ among eligible respondents.

\section{Panel II: Physician Questions}

In the next set of questions, you will be presented with brief clinical descriptions for three different patients. For each, you will be asked a series of questions regarding how you would be likely to treat that patient were he or she in your care.

PATIENT A - CARDIOLOGIST - For this question, think about a patient with stable angina whose symptoms and cardiac risk factors are now well controlled on current medical therapy. In general, how frequently do you schedule routine follow-up visits for a patient like this?

*Answer recorded in number of months

PATIENT A - PCPs: In general, how frequently do you schedule routine follow-up visits for a patient with well-controlled hypertension?

*Answer recorded in number of months 
PATIENT B: A 75 year old man with severe (Class IV) congestive heart failure from ischemic heart disease, is on maximal medications and has effective disease management counseling. His symptoms did not improve after recent angioplasty and stent placement and $C A B G$ is not an option. He is uncomfortable at rest. He is noted to have frequent, asymptomatic nonsustained VT on cardiac monitoring. He has adequate health insurance to cover tests and medications. At this point, for a patient presenting like this, how often would you arrange for each of the following?

CARDIOLOGIST SURVEY

a - Repeat angiography

b - Initiate antiarryghmic therapy

c - Recommend an Implantable Cardiac Defibrilator (ICD)

d - Recommend biventricular pacemaker for cardiac resynchronization

e - Initiate or continue discussions about palliative care

POSSIBLE RESPONSES

1 Always/Almost always

2 Most of the time

3 Some of the time

4 Rarely

5 Never

PATIENT C: An 85 year old male patient has severe (Class IV) congestive heart failure from ischemic heart disease, is on maximal medications, and is not a candidate for coronary revascularization. He is on 2 liters per minute of supplemental oxygen at home. He presents to your office with worsening shortness of breath and difficulty sleeping due to orthopnea. Office chest xray confirms severe congestive heart failure. Oxygen saturation was $85 \%$ and increased to $94 \%$ on 4 liters and the patient is more comfortable. He has adequate health insurance to cover tests and medications. At this point, for a patient presenting like this, how often would you arrange for each of the following?

PCP and CARDIOLOGIST SURVEY

a - Allow the patient to return home on increased oxygen and increased diuretics

b - Admit to the hospital for aggressive diuresis (not to the ICU/CCU)

c - Admit to the ICU/CCU for intensive therapy and monitoring

d - Place a pulmonary artery catheter for hemodynamic optimization

e - Recommend biventricular pacemaker for cardiac resynchronization

$\mathrm{f}$ - Initiate or continue discussions about palliative care

POSSIBLE RESPONSES (both surveys)

1 Always/Almost always

2 Most of the time

3 Some of the time

4 Rarely

5 Never 

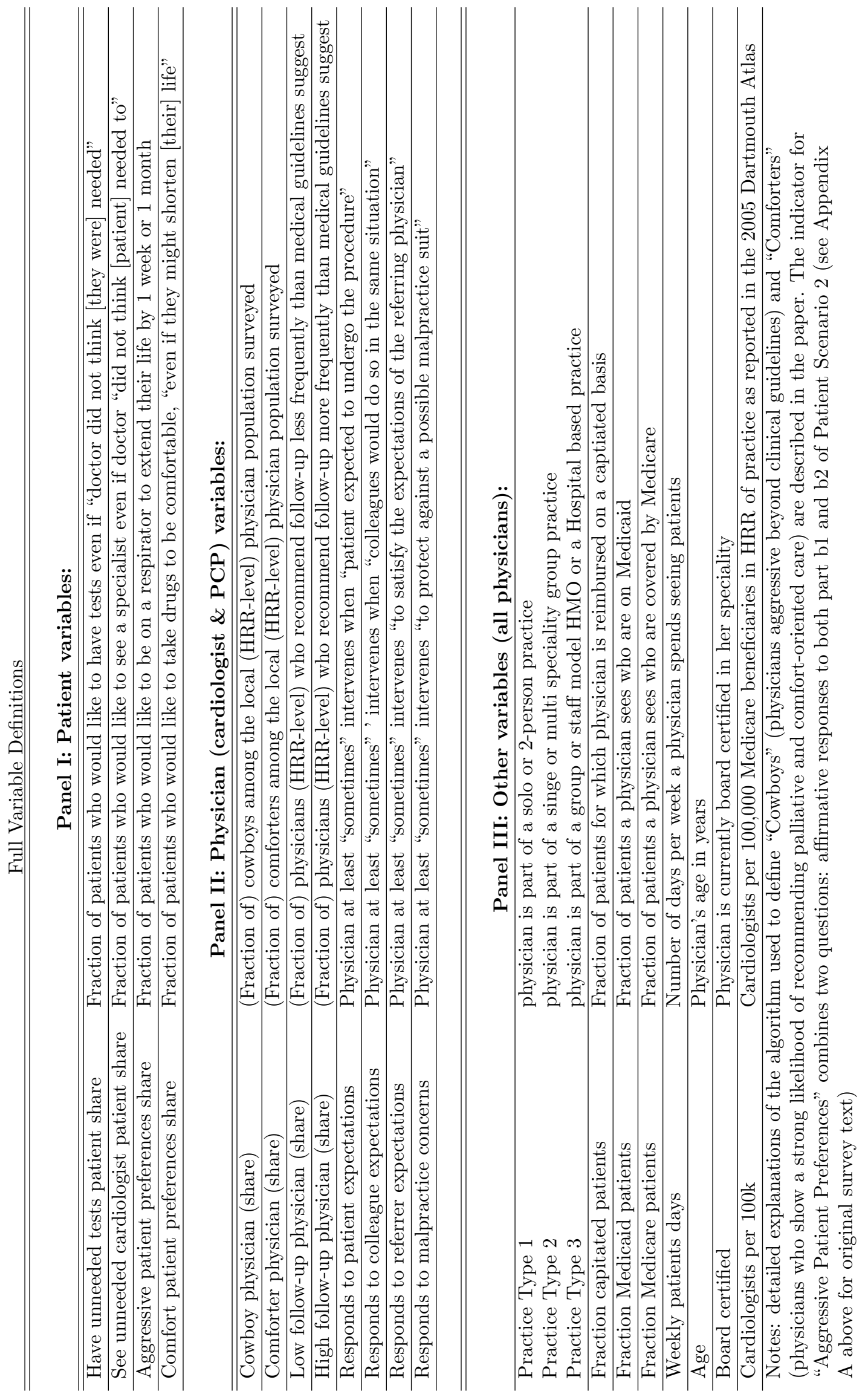


\section{Appendix C: Further Results}

Appendix Table C1: Regression Estimates of Ln Medicare Expenditures in the Last Two Years (Cardiologists Only)

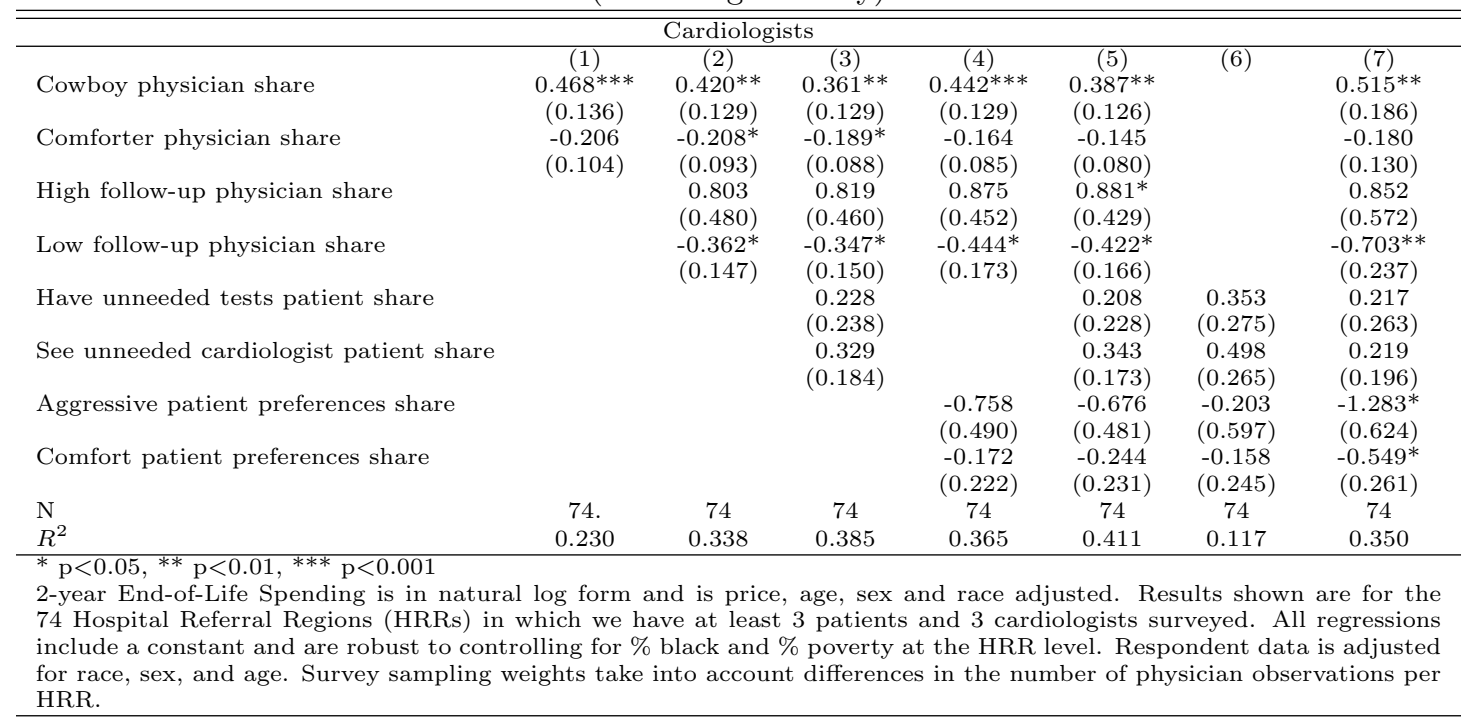

Appendix Table C2: Regression Estimates of Ln Medicare Expenditures in the Last Two Years (PCPs Only)

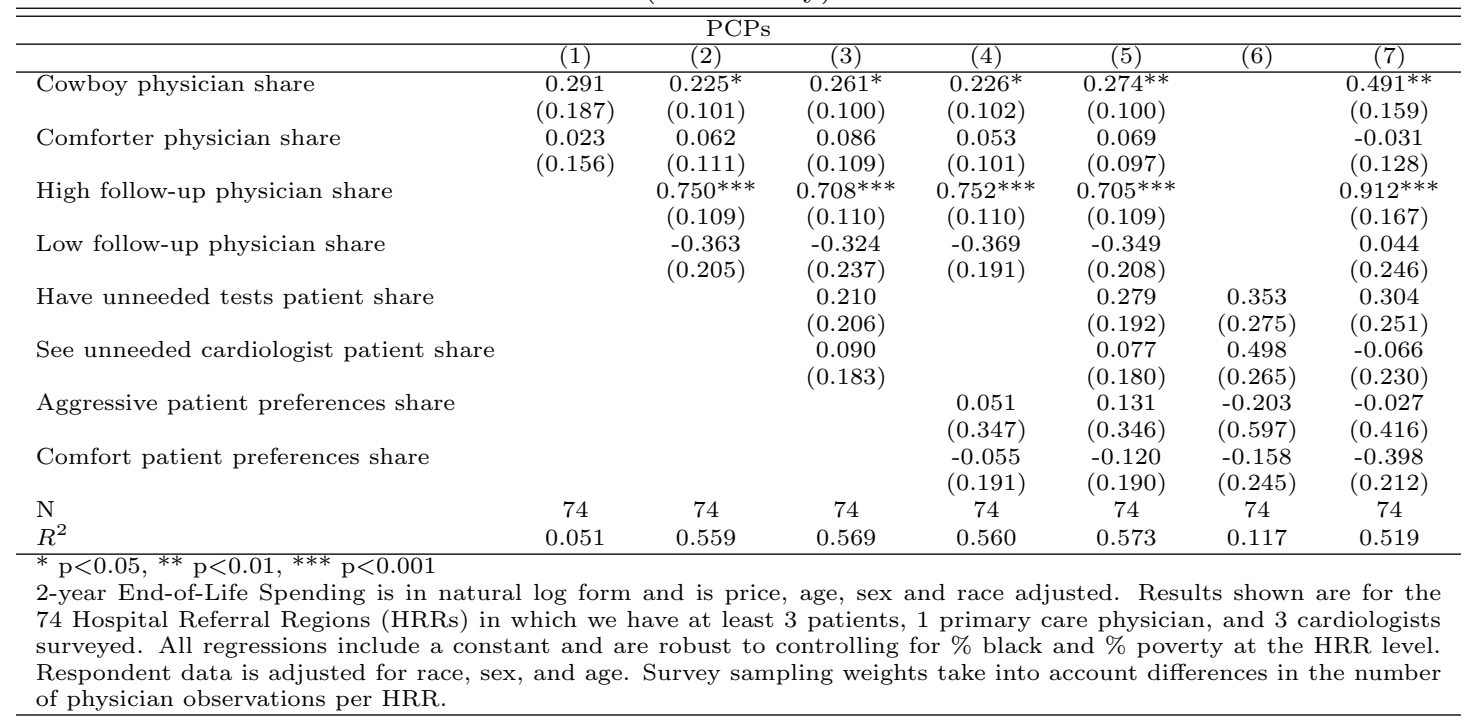


Appendix Table C3: Expanded Regression Estimates of Ln Medicare Expenditures in the Last Two Years

\begin{tabular}{|c|c|c|c|c|}
\hline \multicolumn{5}{|c|}{ Combined Sample: Cardiologists and PCPs } \\
\hline & $(1)$ & $(2)$ & $(3)$ & $(4)$ \\
\hline Cowboy physician share & $\begin{array}{c}0.887^{* * *} \\
(0.201)\end{array}$ & $\begin{array}{c}0.810^{* * *} \\
(0.182)\end{array}$ & $\begin{array}{c}0.942^{* * *} \\
(0.224)\end{array}$ & $\begin{array}{c}0.854^{* * *} \\
(0.184)\end{array}$ \\
\hline Comforter physician share & $\begin{array}{c}-0.311 \\
(0.162)\end{array}$ & $\begin{array}{c}-0.325 \\
(0.170)\end{array}$ & $\begin{array}{l}-0.301 \\
(0.167)\end{array}$ & $\begin{array}{l}-0.326 \\
(0.172)\end{array}$ \\
\hline High follow-up physician share & $\begin{array}{c}1.272^{* * *} \\
(0.238)\end{array}$ & $\begin{array}{c}1.140 * * * \\
(0.252)\end{array}$ & $\begin{array}{c}1.309 * * * \\
(0.230)\end{array}$ & $\begin{array}{c}1.172^{* * *} \\
(0.252)\end{array}$ \\
\hline Low follow-up physician share & $\begin{array}{l}-0.556 \\
(0.290)\end{array}$ & $\begin{array}{c}-0.429 \\
(0.229)\end{array}$ & $\begin{array}{c}-0.575 \\
(0.290)\end{array}$ & $\begin{array}{l}-0.450 \\
(0.234)\end{array}$ \\
\hline Fraction capitated patients & & $\begin{array}{c}0.001 \\
(0.003)\end{array}$ & & $\begin{array}{c}0.001 \\
(0.003)\end{array}$ \\
\hline Fraction Medicaid patients & & $\begin{array}{c}-0.003 \\
(0.010)\end{array}$ & & $\begin{array}{c}-0.003 \\
(0.009)\end{array}$ \\
\hline Single/multi speciality group practice & & $\begin{array}{c}-0.185 \\
(0.226)\end{array}$ & & $\begin{array}{c}-0.183 \\
(0.232)\end{array}$ \\
\hline Group/staff HMO or hospital-based practice & & $\begin{array}{l}0.439^{*} \\
(0.218)\end{array}$ & & $\begin{array}{c}0.400 \\
(0.212)\end{array}$ \\
\hline Responds to patient expectations & & & $\begin{array}{c}0.212 \\
(0.209)\end{array}$ & $\begin{array}{c}0.158 \\
(0.189)\end{array}$ \\
\hline Responds to colleague expectations & & & $\begin{array}{c}-0.062 \\
(0.180)\end{array}$ & $\begin{array}{c}-0.011 \\
(0.175)\end{array}$ \\
\hline Responds to referrer expectations & & & $\begin{array}{c}-0.005 \\
(0.180)\end{array}$ & $\begin{array}{c}0.004 \\
(0.170)\end{array}$ \\
\hline Responds to malpractice concerns & & & $\begin{array}{c}-0.209 \\
(0.171)\end{array}$ & $\begin{array}{c}-0.126 \\
(0.159)\end{array}$ \\
\hline $\mathrm{N}$ & 74 & 74 & 74 & 74 \\
\hline$R^{2}$ & 0.555 & 0.597 & 0.565 & 0.601 \\
\hline $\begin{array}{l}* \mathrm{p}<0.05,{ }^{*} \mathrm{p}<0.01,{ }^{* *} \mathrm{p}<0.001 \\
2 \text {-year End-of-Life Spending is in natural log } \\
\text { Results shown are for the } 74 \text { Hospital Referr } \\
\text { patients, } 1 \text { primary care physician, and } 3 \text { ca } \\
\text { where missing data forced us to drop one reg } \\
\text { for the fraction of primary care physicians in } \\
\text { black and \% poverty at the HRR level. Res } \\
\text { Survey sampling weights take into account dif } \\
\text { per HRR. }\end{array}$ & $\begin{array}{l}\text { form and } \\
\text { Regions } \\
\text { liologists s } \\
\text { on. All re } \\
\text { he sample, } \\
\text { ondent dat } \\
\text { rences in t }\end{array}$ & $\begin{array}{l}\text { price, age } \\
\text { HRRs) in } \\
\text { rveyed, ex } \\
\text { essions in } \\
\text { and are ro } \\
\text { is adjuste } \\
\text { e number }\end{array}$ & $\begin{array}{l}\text { sex and ra } \\
\text { iich we ha } \\
\text { pt in Mod } \\
\text { lde a cons } \\
\text { ist to cont } \\
\text { for race, } \\
\text { physician }\end{array}$ & $\begin{array}{l}\text { adjusted. } \\
\text { at least } 3 \\
\text { s } 2 \text { and } 4 \text {, } \\
\text { nt, control } \\
\text { ling for \% } \\
\text { x and age. } \\
\text { servations }\end{array}$ \\
\hline
\end{tabular}




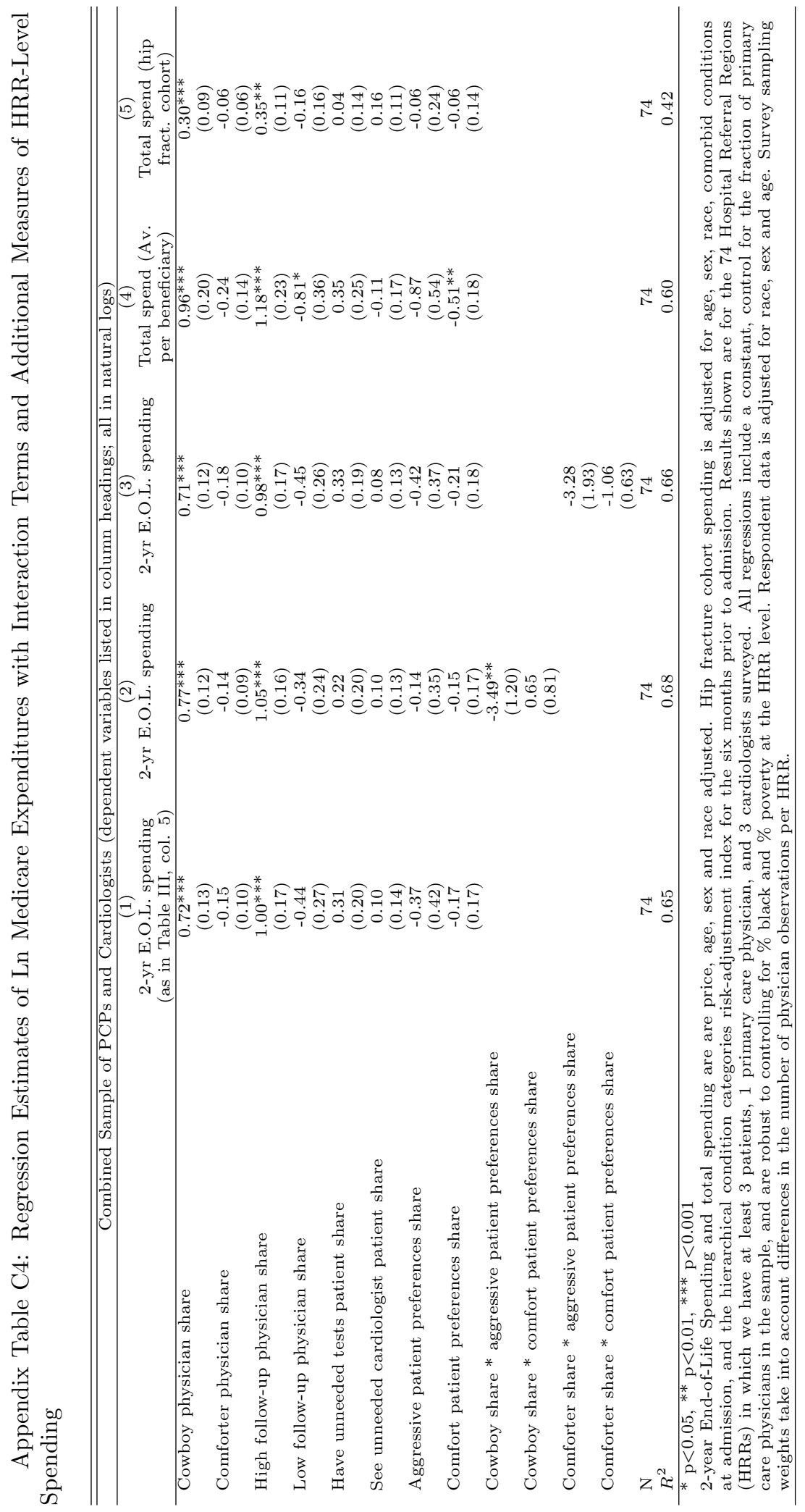


Appendix Table C5: Summary Statistics for Additional AMI Data in Table 4

\begin{tabular}{|c|c|c|c|}
\hline \multicolumn{4}{|c|}{$(137$ HRRs, $\mathrm{N}=603,457)$} \\
\hline & Mean & Median & $\begin{array}{l}\text { Standard } \\
\text { Deviation }\end{array}$ \\
\hline 1-Year Medicare Expenditures & 45,827 & 32,859 & 42,208 \\
\hline Median ZIP Household Income & 56,251 & 50,623 & 22,497 \\
\hline Log 1-Year Medicare Expenditures & 10.41 & 10.40 & 0.80 \\
\hline 1-Year Survival & 0.68 & 1.00 & 0.47 \\
\hline Same Day PCI (stent) & 0.26 & 0.00 & 0.44 \\
\hline Age & 78.85 & 79.00 & 8.28 \\
\hline Fraction Black & 0.08 & 0.00 & 0.26 \\
\hline Fraction Hispanic & 0.02 & 0.00 & 0.13 \\
\hline Fraction Asian & 0.01 & 0.00 & 0.12 \\
\hline Fraction Female & 0.50 & 1.00 & 0.50 \\
\hline Average $\mathrm{HCC}$ & 1.73 & 1.31 & 1.35 \\
\hline Vascular Disease & 0.08 & 0.00 & 0.27 \\
\hline Pulmonary Disease & 0.17 & 0.00 & 0.38 \\
\hline Dementia & 0.03 & 0.00 & 0.18 \\
\hline Renal Disease & 0.18 & 0.00 & 0.38 \\
\hline Cancer (non-metastatic) & 0.05 & 0.00 & 0.22 \\
\hline Cancer (metastatic) & 0.01 & 0.00 & 0.11 \\
\hline Congestive Heart Failure & 0.40 & 0.00 & 0.49 \\
\hline AIDS & 0.00 & 0.00 & 0.02 \\
\hline Plegia (stroke) & 0.00 & 0.00 & 0.05 \\
\hline Liver disease & 0.00 & 0.00 & 0.06 \\
\hline Diabetes & 0.26 & 0.00 & 0.44 \\
\hline Rheumatologic Disease & 0.01 & 0.00 & 0.10 \\
\hline Peripheral Vascular Disease & 0.02 & 0.00 & 0.12 \\
\hline AMI Location: Anterolateral & 0.02 & 0.00 & 0.14 \\
\hline Anterior wall & 0.07 & 0.00 & 0.26 \\
\hline Inferolateral & 0.02 & 0.00 & 0.13 \\
\hline Inferoposterior & 0.01 & 0.00 & 0.11 \\
\hline All other inferior & 0.09 & 0.00 & 0.28 \\
\hline
\end{tabular}


Supplementary Figure 1: Radar Plots of Select High Follow-up Frequency and Cowboy Prevalence by HRR

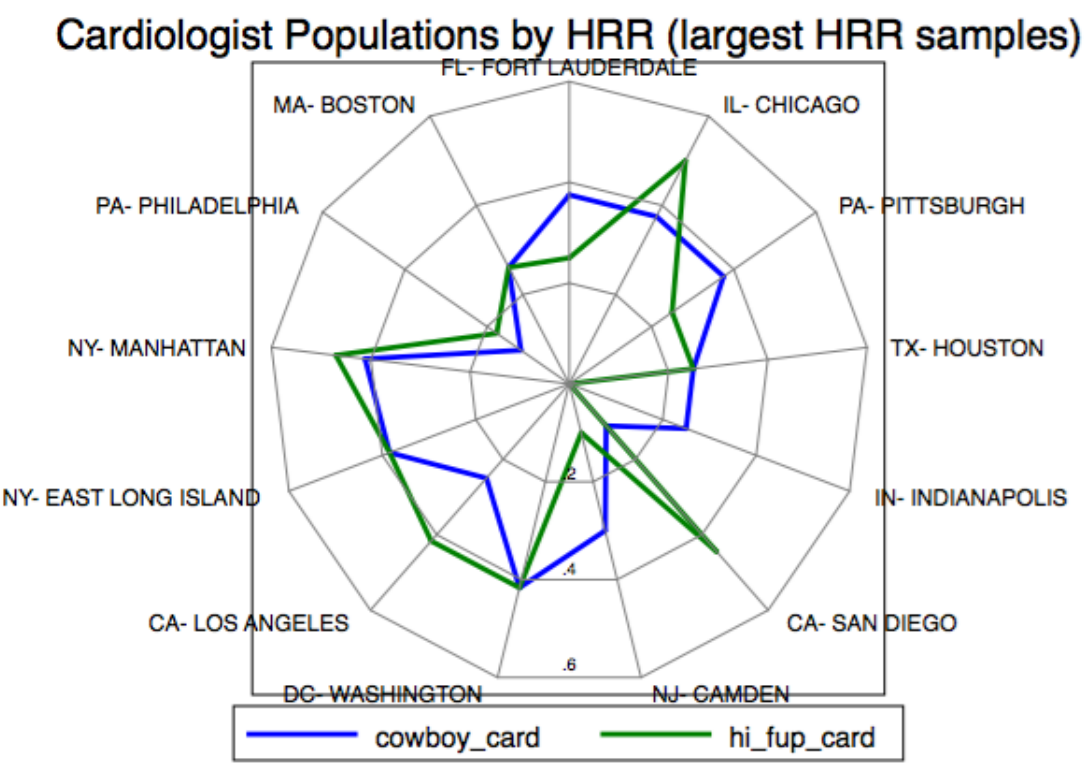

Center is at 0

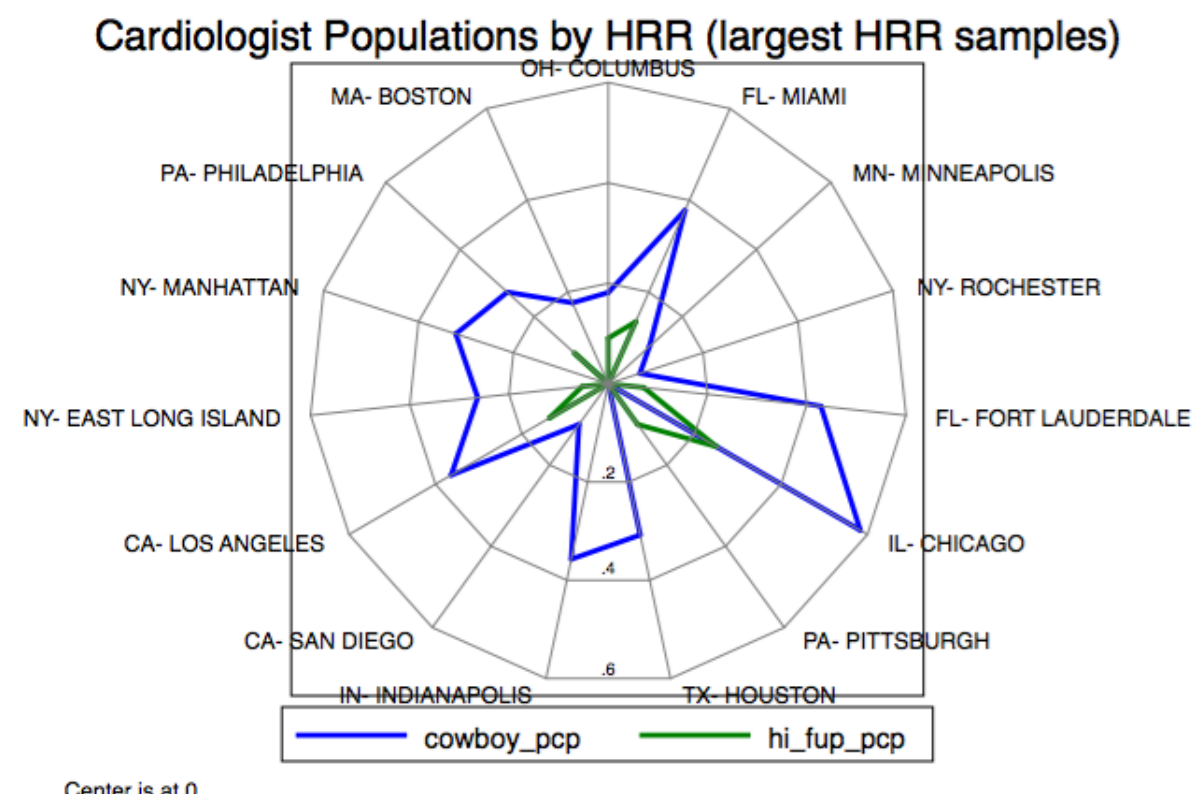

This figure provides additional visual evidence of the relationship between cowboy status and recommended follow-up frequency for the HRRs with the greatest number of respondents; a point that is further out on the scale corresponds to a larger fraction of physicians. 